\title{
Analysis of primary visual cortex in dementia with Lewy bodies indicates GABAergic involvement associated with recurrent complex visual hallucinations
}

\author{
Ahmad A. Khundakar ${ }^{1 \dagger}$, Peter S. Hanson ${ }^{2 \dagger}$, Daniel Erskine ${ }^{1,2}$, Nichola Z. Lax ${ }^{1,3}$, Joseph Roscamp², Evangelia Karyka ${ }^{2}$, \\ Eliona Tsefou ${ }^{2}$, Preeti Singh², Simon J. Cockell ${ }^{4}$, Andrew Gribben², Lynne Ramsay ${ }^{2}$, Peter G. Blain², \\ Urs P. Mosimann ${ }^{5}$, Deborah J. Lett ${ }^{1}$, Matthias Elstner ${ }^{6}$, Douglass M. Turnbull ${ }^{1,3}$, Charles C. Xiang ${ }^{7}$, \\ Michael J. Brownstein 7 , John T. O'Brien ${ }^{8,9}$, John-Paul Taylor ${ }^{8}$, Johannes Attems' ${ }^{1}$, Alan J. Thomas ${ }^{8}$, \\ Ian G. McKeith ${ }^{8}$ and Christopher M. Morris ${ }^{1,2,7^{*}}$
}

\begin{abstract}
Dementia with Lewy bodies (DLB) patients frequently experience well formed recurrent complex visual hallucinations $(\mathrm{RCVH})$. This is associated with reduced blood flow or hypometabolism on imaging of the primary visual cortex. To understand these associations in DLB we used pathological and biochemical analysis of the primary visual cortex to identify changes that could underpin RCVH. Alpha-synuclein or neurofibrillary tangle pathology in primary visual cortex was essentially absent. Neurone density or volume within the primary visual cortex in DLB was also unchanged using unbiased stereology. Microarray analysis, however, demonstrated changes in neuropeptide gene expression and other markers, indicating altered GABAergic neuronal function. Calcium binding protein and GAD65/67 immunohistochemistry showed preserved interneurone populations indicating possible interneurone dysfunction. This was demonstrated by loss of post synaptic GABA receptor markers including gephyrin, GABARAP, and Kif5A, indicating reduced GABAergic synaptic activity. Glutamatergic neuronal signalling was also altered with vesicular glutamate transporter protein and PSD-95 expression being reduced. Changes to the primary visual cortex in DLB indicate that reduced GABAergic transmission may contribute to RCVH in DLB and treatment using targeted GABAergic modulation or similar approaches using glutamatergic modification may be beneficial.
\end{abstract}

Keywords: Dementia with Lewy bodies, a-synuclein, Primary visual cortex, Hallucinations, Alzheimer's disease

\section{Introduction}

Dementia with Lewy bodies (DLB) accounts for up to $20 \%$ of all dementia cases at autopsy [1]. Clinically DLB is associated with at least two of the following three core clinical features: recurrent complex visual hallucinations $(\mathrm{RCVH})$, fluctuating cognition and parkinsonism [2] or

\footnotetext{
* Correspondence: c.m.morris@ncl.ac.uk

${ }^{\dagger}$ Equal contributors

${ }^{1}$ Edwardson Building, Institute of Neuroscience, Newcastle University, Campus for Ageing and Vitality, Westgate Road, Newcastle upon Tyne NE4 $5 P L$, UK

${ }^{2}$ Medical Toxicology Centre, Newcastle University, Wolfson Building, Claremont Place, Newcastle NE2 4AA, UK

Full list of author information is available at the end of the article
}

one of these and one supportive feature (neuroleptic sensitivity, abnormal dopaminergic imaging of striatum, or rapid eye movement sleep behaviour disorder) [3]. It is the presence of $\mathrm{RCVH}$, however, that has been suggested to be one of the most characteristic features of the disorder, and is associated with increased patient and caregiver distress and greater likelihood of nursing home admission and hospitalisation [2].

The RCVH in DLB are described as being well formed and involve animals, people, and objects [4] and show some similarities with the visual hallucinations seen in Charles-Bonnet syndrome and those following occipital infarction [5, 6]. Illusions and misperceptions are also 
experienced, and the occurrence of passage and presence hallucinations are also common, as with Parkinson's disease (PD) and Parkinson's disease with dementia (PDD) [7-9]. Whilst RCVH are one of the core clinical symptoms of DLB, their aetiological basis is essentially unknown. DLB subjects do show hypoperfusion and glucose hypometabolism in the medial occipital lobe including the primary and secondary visual cortices [10$12]$, which is associated with the visuoperceptual problems common to both DLB and PDD and may lead to misidentification or misinterpretation of objects and images [13]. Such visuoperceptual problems may indicate parietal and occipital dysfunction and relate to the $\mathrm{RCVH}$ experienced in DLB. RCVH have been suggested to be due to cortical atrophy, although most neuroradiological studies do not find significant atrophy of the medial occipital cortex in DLB [14-17] or in PD or PDD $[14,15,18]$. However, some studies show cortical thinning in the cuneus, precuneus and pericalcarine regions in DLB [19]. Whilst there appears to be involvement of the lateral occipital cortex in DLB $[11,12]$, the only significant pathology reported is spongiform change and gliosis in the medial occipital white matter [20], although this has not been observed in all studies [21, 22]. Ocular pathologies may also contribute to $\mathrm{RCVH}$ but these are common in elderly individuals, in addition to DLB and PD, where clouding, increased central and peripheral corneal opacity, and macular degeneration also occur $[23,24]$. Changes in visual perception with decreased capacity to identify motion in spatial suppression tasks [25], and decreased motion perception [26, 27], along with reduced acuity [28] and ability to determine images in the peripheral fields are seen in older persons [29]. Changes in visual acuity are also common in DLB [13] and in PD [13, 23], although these are not more frequent than cognitively normal older individuals and the presence of retinal changes in PD, whilst suggested, has not been substantiated in some studies [30]. The interaction between reduced higher cortical activity and an altered proximal visual system associated with ageing may therefore contribute to the RCVH seen in DLB.

The well-formed nature of $\mathrm{RCVH}$ in DLB suggests that the ventral visual stream $[31,32]$ is affected. The ventral stream from the primary visual cortex projects to the temporal lobe, including the amygdala. These areas contain relatively high numbers of LB and it has been speculated that this may contribute to $\mathrm{RCVH}$ in DLB [33-35] although no differences between hallucinating and non-hallucinating cases have been observed. Nonetheless, high densities of Lewy bodies in the parahippocampal gyrus have been suggested to relate to early development of $\mathrm{RCVH}$ in both DLB [22] and also PD [24]. Alpha $(\alpha)$-synuclein pathology in the retina in DLB [36] and cholinergic dysfunction in the medial occipital cortex in DLB [37] have also been observed indicating that pathological changes in the eye and biochemical changes in the primary visual cortex could potentially contribute to RCVH in DLB [38].

Since the possible changes in DLB that could contribute to $\mathrm{RCVH}$ do not stand alone but are part of the highly complex visual system, the question arises as to what are the molecular substrates of RCVH in DLB. Given the paucity of information on pathology in the primary visual cortex in DLB, but with the presence of a marked and specific hypometabolic deficit in this region in DLB [11, 39], it is possible that biochemical abnormalities in the visual cortex contribute to RCVH. We therefore explored this issue and describe here the analysis of the changes in the primary visual cortex in DLB using a combination of pathology and stereology to identify pathological and neuronal involvement, coupled with transcriptomic analysis of RNA and complimentary protein determination to determine the biochemical systems involved. A comparison group of individuals with Alzheimer's disease (AD) was used to determine disease specific changes.

\section{Materials and methods Clinical samples}

All procedures were approved by the Local Research Ethics Committee and tissue was obtained from the Newcastle Brain Tissue Resource (NBTR), a UK Human Tissue Authority approved Research Tissue Bank. The DLB and AD cases used in both pathological or biochemical series were from several local prospective clinical studies, with participants having clinical assessments repeated annually where appropriate until death and agreeing to donate tissue for research purposes. Clinical diagnoses of DLB and AD were made according to international consensus criteria [3] and NINCDS ADRDA criteria [40], respectively. Healthy control subjects were obtained from NBTR and all such cases had received thorough case note review to confirm they did not have cognitive impairment and had normal everyday function at time of death. The presence of eye disease was identified through case note review and in all cases this was identified by standard eye investigations. All cases had neuropathological confirmation of either having DLB, $\mathrm{AD}$, or were neuropathologically normal according to established criteria [3, 41-44]. Cases of DLB had the presence of visual hallucinations documented by patient and informant interview through standard clinical interview according to consensus criteria [3] or were without any documented RCVH (1 case), whilst AD cases showed an absence of any prior history of RCVH. Tissue was obtained at post mortem, and the delay from death to freezing and fixation was noted. 
Tissue from the left hemisphere was rapidly frozen at $-80{ }^{\circ} \mathrm{C}$ using pre-cooled copper blocks as approximately $1 \mathrm{~cm}$ thick slices and stored at $-80{ }^{\circ} \mathrm{C}$ until use. The right hemisphere was fixed in $10 \%$ formalin and processed by paraffin wax embedding.

For histopathological investigation, a $1 \mathrm{~cm}$-thick coronal block of fixed tissue of the occipital lobe was cut into a series of $25 \times 40-\mu \mathrm{m}$-thick tissue slices from a pre-defined paraffin-embedded coronal block containing the relevant portion of the middle of the primary visual cortex from a subset of patients (See Additional file 1: Table S1). Three of the 25 sections were sampled at equally spaced intervals (every eight sections) and stained with cresyl fast violet. The quality of each section was checked for consistency and the slides coded (CMM) to ensure that all analysis was carried out blind to diagnosis. The layers of the primary visual cortex were delineated and all measurements were taken from the cortical strip directly surrounding the calcarine sulcus. Additional paraffin sections $(6-10 \mu \mathrm{m})$ were taken for pathological investigation and stained for myelin (Loyez stain), and with haematoxylin and eosin to show general structure. Immunohistochemical investigations of pathology used a standard $A B C$ peroxidise method using anti- $\alpha$-synuclein (KM1, Leica), anti-amyloid $\beta$ peptide (4G8, Signet), and anti-phosphorylated tau (AT8, Thermo) and quantified using a standardised morphometric approach $[45,46]$ (antibody details given in Additional file 2: Table S6).

\section{Stereology}

Neuronal density and volume was estimated within layers of the primary visual cortex using stereological analysis software (Stereologer, Chester, MD, USA) to apply the optical disector [47] and rotator [48] methods to obtain the density and volume estimates, respectively, as in our previous studies $[49,50]$. Neurones were identified using standardised criteria: the presence of a Nisslstained cytoplasm, pale nucleus and single identifiable nucleolus in cells that were not spherical unlike glial cells. The sections were viewed in oil using a Zeiss Photomicroscope at $\mathrm{x} 100$ objective and a numerical aperture of 1.25. The microscope was attached to a JVC colour video camera TK-C1360B (JVC UK Ltd, London, $\mathrm{UK})$, a motorised $x$ - and $y$-axis stage accurate to $1 \mu \mathrm{m}$ (Optiscan ES110, Prior Scientific Instruments Ltd, Cambridge, UK) and a Heidenhain $z$-axis depth gauge accurate to $0.5 \mu \mathrm{m}$ (Heidenhain GB Ltd, London, UK) to ensure accurate measurement of disector depth.

Based on our previous investigations a random sampling strategy was used and estimates were conducted using one disector field per field of view and over 120 counts were made per layer examined in each subject to ensure precise estimates. Each disector frame measured
$50 \mu \mathrm{m}$ long, $50 \mu \mathrm{m}$ wide and $15 \mu \mathrm{m}$ deep, with a guard area of at least $4 \mu \mathrm{m}$ taken (average $\mu \mathrm{m}$ ) above and below the 3-D disector box, dependent on section thickness measurement. The mean coefficient of error (CE) for the overall neuronal and glial estimates were calculated using the Gundersen-Jensen method [51], as previously $[49,50]$ and showed that the mean CE for neuronal volume and density reached an acceptable level of precision in all layers in all cases measured $(P<0.15)$ [51]. There was no significant difference in demographic, clinical and histopathological information on the study sample (summarised in Additional file 1: Table S1). There were no significant differences between the groups in age, gender, tissue $\mathrm{pH}$, duration of tissue fixation (d.f. $=25, P>0.05$ for all measures), or postmortem interval. Mean $( \pm \mathrm{SD})$ section thickness across all layers was comparable (d.f. $=25, p=0.70$ ) between control $(31.82[1.00] \mu \mathrm{m}), \mathrm{AD}(31.58[0.79] \mu \mathrm{m})$ or DLB $(31.89[0.37] \mu \mathrm{m})$ groups after processing.

\section{RNA isolation}

The primary visual cortex was identified in blocks of snap frozen tissue and approximately $50 \mathrm{mg}$ of grey matter was dissected at $-20{ }^{\circ} \mathrm{C}$ from a second series of 13 DLB, 12 control, and 13 AD cases with 12 DLB, 12 Control and $11 \mathrm{AD}$ cases having RNA of sufficient quality for use and using identical clinical and pathological criteria to the group used for pathological investigation (see Additional file 3: Table S2) and placed in 5-10 volumes of pre-cooled RNAlater solution (Ambion, Warrington, UK) and stored at $-80{ }^{\circ} \mathrm{C}$. Tissue was removed from RNAlater and rapidly homogenised in TRIReagent (Ambion) and stored at $-80{ }^{\circ} \mathrm{C}$. RNA was extracted using a spin column method as per the manufacturer's instructions (Ribopure, Ambion) and 1ug of RNA was DNase-treated (Turbo-DNAase free, Ambion). The RNA concentration was determined using a Nanodrop ND 1000 Spectrophotometer (Nanodrop Technologies) and RNA integrity number (RIN) examined with an Agilent 2100 Bioanalyzer RNA 6000 Nano Assay (Agilent Technologies, Stockport UK) according to the manufacturer's instructions.

\section{Microarray analysis}

Control $(n=12)$ and DLB $(n=12)$ total RNA samples were selected as a subset from the second group of patient material on the basis of tissue $\mathrm{pH}(>6.0)$ and RIN value $(>6.0)$ (see Additional file 3: Table S2) and were analysed using Illumina Human-6 v2 BeadChips with approximately 48,000 transcript probes per chip using a GLP certified facility (Aros, Brensby, Denmark). Data was imported into $\mathrm{R}, \log 2$ transformed using a Variance Stabilizing Transformation [52] and Robust Spline Normalisation algorithm designed for Beadarray data [53]. 
Following removal of failed samples and outliers using hierarchical clustering which excluded two array samples, significantly altered transcripts were identified in the limma package [54] and differentially expressed genes identified by applying cut-offs of $p$-Value $<0.05$ (Benjamini-Hochberg FDR correction [55]), and an absolute fold-change of greater than 2 . To identify systems that may be altered/associated with DLB in the primary visual cortex we used Gene Ontology (GO) to identify biological process, molecular function and cellular component annotations using the GOstats package to test gene lists for over-represented terms [56] and also Kyoto Encyclopaedia of Genes and Genomes (KEGG) biochemical pathways.

\section{q-RT-PCR}

Reverse transcription of RNA was performed on $1 \mu \mathrm{g}$ of total RNA using oligo $(\mathrm{dT})_{12-18}$ primer (Invitrogen, Warrington, UK), SupeRNase Inhibitor (Ambion), and Superscript III Reverse Transcriptase at $50{ }^{\circ} \mathrm{C}$ and samples stored at $-80{ }^{\circ} \mathrm{C}$ until use. Semi-quantitative RTPCR was performed in triplicate using Taqman $^{\circledR}$ assays (see Additional file 4: Table S5; Applied Biosystems, Warrington, UK) using Taqman ${ }^{\odot}$ Universal PCR Master Mix (Applied Biosystems). A total of 35 different brain tissue samples with total RNA of RIN $>6.0$ were analysed by q-RT-PCR with 11 control, 12 DLB, and 12 AD subjects used. ABI PRISM ${ }^{\diamond}$ Sequence Detection System software was used to generate $2^{-\Delta \Delta C T}$ values based on the comparative CT method with GAPDH mRNA as a reference [57]. To compare the relative gene expression, a Mann Whitney test was carried out using $2^{-\Delta \Delta C T}$ values with significance level of $P<0.05$.

\section{Protein determination}

Tissue blocks from DLB (mean $\mathrm{pH} 6.3 \pm 0.3$ ), control (mean pH $6.3 \pm 0.4$ ), and AD cases (mean pH $6.0 \pm 0.4$ ) (see case details, Additional file 3: Table S2) of the occipital lobe were brought to $-20{ }^{\circ} \mathrm{C}$ in a freezing cabinet and the primary visual cortex identified. Primary visual cortex tissue and a small amount of underlying white matter were isolated using a pre-cooled scalpel. Extraction was performed by homogenising 100-150 mg of tissue using a rotor stator type homogeniser in ice cold lysis buffer containing $0.2 \mathrm{M}$ tetraethyl ammonium bicarbonate, pH 7.2 (TEAB; Sigma), 1 mM EDTA, and protease inhibitor tablets (Complete, Roche, Burgess Hill, UK) and samples stored at $-80{ }^{\circ} \mathrm{C}$. Samples were thawed, made to $0.02 \%$ sodium dodecyl sulphate and sonicated on ice in a sonicating water bath for $20 \mathrm{~min}$ before protein quantitation was performed using a BCA Protein Assay kit (Pierce, Cramlington, UK).

Proteins (5-20 $\mu \mathrm{g}$ of protein per sample) were separated using NuPAGE 12 \% Bis-Tris gels (Invitrogen) with 1x SDS NuPAGE MOPS Running Buffer containing NuPAGE Antioxidant (Invitrogen). Proteins in the gel were transferred to nitrocellulose membranes using an iBlot device (Invitrogen). Membranes were stained with Ponceau S solution (Sigma) to ensure equal protein loading, destained with $1 \mathrm{x}$ Tris-Buffered Saline (TBS) $0.2 \%$ Tween 20, and stored in 1x TBS $0.2 \%$ Tween 20 at $4{ }^{\circ} \mathrm{C}$ overnight. The membrane was incubated with $5 \%$ dried milk in 1x TBS $0.2 \%$ Tween 20 for 30 min at room temperature to block non-specific protein binding sites and incubated overnight with primary antibody (see Additional file 2: Table S6) diluted in $5 \%$ dried milk in $1 \mathrm{x}$ TBS $0.2 \%$ Tween 20 at $4{ }^{\circ} \mathrm{C}$ with agitation. Membranes were then washed for 10 min intervals 3 times with $1 \mathrm{x}$ TBS $0.2 \%$ Tween 20 and incubated a further 30 min with the appropriate horseradish peroxidase conjugated secondary antibody at room temperature. Membranes were washed for $1 \mathrm{~h}$ with four washes of TBS $0.2 \%$ Tween 20 then proteins visualised by Enhanced Chemiluminescence (GE, Amersham, Bucks, UK) and detected using x-ray film (Fuji, Fisher Scientific, Loughborough, UK). Protein bands were subsequently quantified using Image-J (NIH). Target protein expression was determined by normalising to GAPDH protein expression.

Validated commercial ELISA assays against BDNF (Promega Corporation, Madison, WI, USA), somatostatin, and neuropeptide Y (Cambridge Bioscience, Cambridge, UK) were used according to the manufacturer's instructions. Samples of primary visual cortex tissue homogenates were thawed on ice and centrifuged at 16,000 x g for $20 \mathrm{~min}$ at $4{ }^{\circ} \mathrm{C}$ and the supernatant collected and diluted 1:20-1:50 in assay diluent buffer and applied to prepared assay plates. Samples were read along with standards using a Biotek Synergy Plate Reader. Protein in supernatant samples was determined using a BCA Protein Assay kit (Pierce) and specific peptide levels expressed as ng or pg peptide/mg protein.

\section{Statistical analysis}

Analysis of pathology and stereology data involved analysis of variance (ANOVA), with pairwise comparison of differences and Bonferroni correction for multiple comparisons. PCR data was analysed using Mann Whitney U tests since the data were not normally distributed and protein data were analysed initially using Levine's f-test to determine homogeneity of variance and differences using two-way unpaired t-tests. In all cases, $P<0.05$ (uncorrected) was considered significant based on a priori data from microarray.

\section{Results}

Pathology

Pathological investigation of the primary visual cortex in relation to $\mathrm{RCVH}$, showed no evidence of $\alpha$-synuclein 
deposition as Lewy bodies or Lewy neurites within primary visual cortex in any DLB case, with some evidence of $\alpha$-synuclein deposition in BA18 as Lewy neurites in DLB cases, and increased deposition as Lewy neurites and occasional Lewy bodies in the lateral occipital cortex (see Fig. 1). The mean intensity of $\alpha$-synuclein staining in three occipital regions was recorded for the primary visual, secondary visual and lateral occipital cortices. No difference was seen in staining intensity between DLB, AD and control cases for overall $\alpha$-synuclein staining intensity. There was no statistically significant difference between the three areas in DLB compared to AD (ANOVA: $\mathrm{F}=(2,147)=$ $1.328, p=0.268$ ). A difference in the intensity of staining was seen between the primary visual, secondary visual and lateral occipital cortices within the DLB group (ANOVA: $\mathrm{F}[2,42]=7.444, p=.002)$, with significantly more staining in secondary visual $(114.49 \pm 2.84, p=0.038)$ and lateral occipital $(119.10 \pm 3.05, p=0.001)$ cortices, compared to primary visual cortex $(104.99 \pm 1.86)$. A similar significant difference between the areas was also seen in the $\mathrm{AD}$

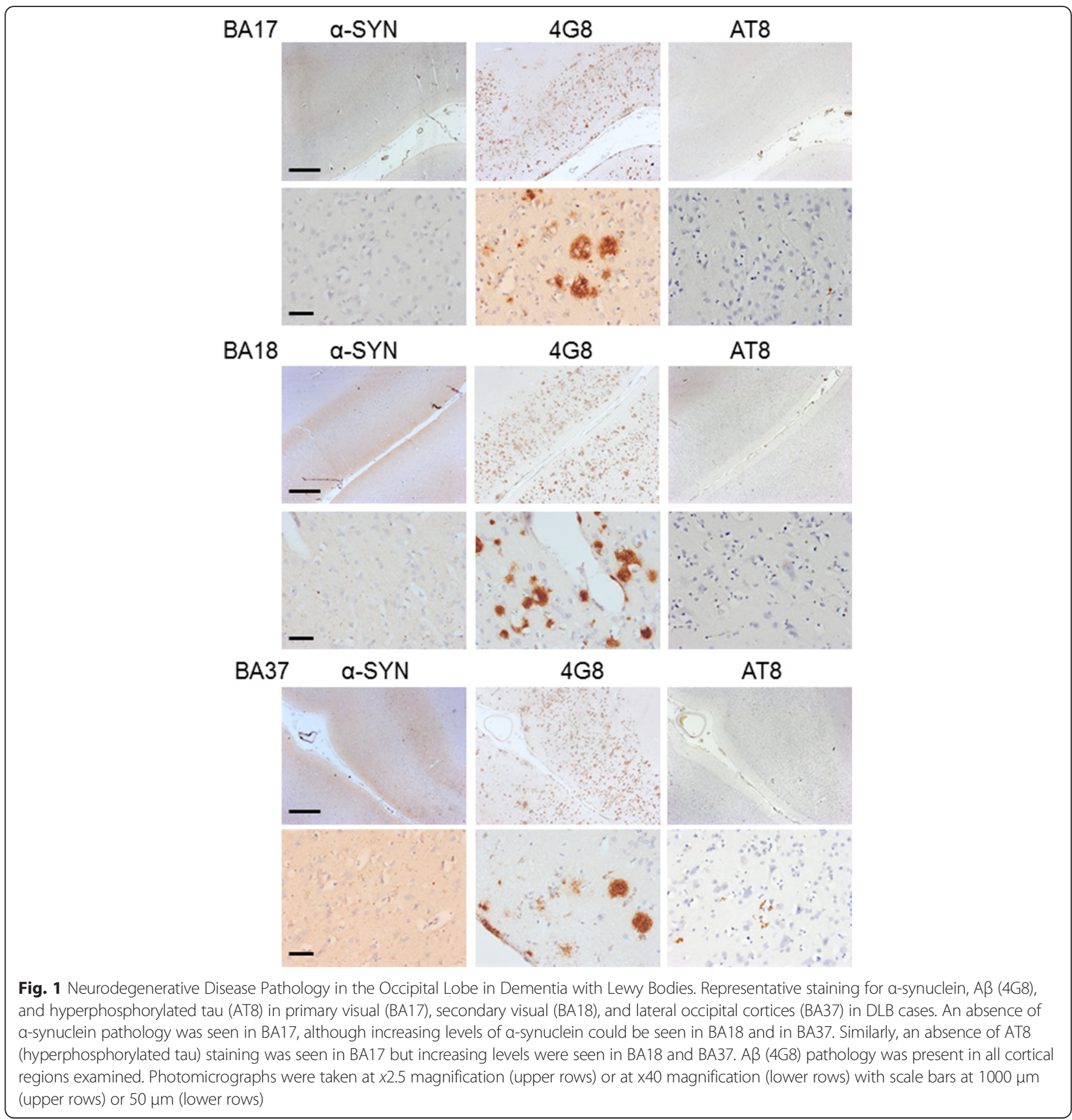


group (ANOVA: $F=(2,147)=32.275, P<0.001$ ), with this being significant between the secondary visual and lateral occipital cortices in $\mathrm{AD}(p=0.440)$. Transcripts for $\alpha$-synuclein mRNA were not significantly altered in DLB compared to controls, and similarly protein analysis of $\alpha$-synuclein monomer $(18 \mathrm{kDa})$ showed no significant change in expression in DLB, and comparable levels of expression were observed between control and AD subjects (see Additional file 5: Table S3), consistent with previous studies [58].

Assessment of amyloid- $\beta$ and tau pathology demonstrated that the primary visual cortex in AD showed a high level of amyloid- $\beta$ pathology in the form of senile plaque and diffuse amyloid- $\beta$ deposition, which was significantly higher than in controls and also higher than in DLB $(P<0.005$ vs control; $P<0.05$ vs DLB, see Additional file 6: Figure $S 1$ ). Amyloid- $\beta$ pathology was found in the occipital cortex in DLB, but was not higher than in cognitively normal controls. No changes in APP mRNA expression were seen in the primary visual cortex using q-RT-PCR in either DLB or AD compared to controls (see Additional file 5: Table S3). Tau pathology, as assessed by AT8 immunostaining, was present throughout the occipital lobe in $\mathrm{AD}$ cases as neurofibrillary tangles and neuropil threads and was significantly higher in the primary visual cortex but was minimal or absent from control and DLB cases $(P<0.05$ vs control; $P<$ 0.05 vs DLB, see Additional file 6: Figure S1). No changes in MAPT (tau) mRNA expression were seen in the primary visual cortex using q-RT-PCR in DLB, or AD cases compared to controls (see Additional file 5: Table S3).

\section{Stereology}

Since neurodegenerative pathology in the primary visual cortex in DLB was not significantly different from that in normal elderly control individuals, neuronal densities were determined in the primary visual cortex. There were no significant differences in neuronal density in any layer of the primary visual cortex between control and DLB or AD groups after multiple comparison analysis (Fig. 2a). However, there was a significant reduction in neuronal volume in layer $4 \mathrm{a}$ in the $\mathrm{AD}$ group $(p=$ 0.042; see Fig. 2b) in comparison to the control group. Furthermore, a significant reduction in neuronal volume in the $\mathrm{AD}(p=0.043)$ versus control group was found across all layers when combined. No significant changes were found in neuronal volume in the DLB group against control or AD groups in any layer of the primary visual cortex. Similarly, since hypoperfusion and hypometabolism is a feature of DLB occipital cortex [11], we determined the presence of capillary density in primary visual cortex in DLB using Glut-1 staining. No alterations in capillary density were observed in either DLB or AD brain compared to age matched controls (not shown) suggesting hypoperfusion and hypometabolism is not associated with altered capillary density.

\section{Microarray}

Owing to the lack of significant $\alpha$-synuclein pathology or of major amyloid- $\beta$ or Tau deposition in DLB and any significant cell loss in the primary visual cortex in DLB, whole genome microarrays were used to determine the changes in gene expression associated with hypoperfusion and hypometabolism. Seventy three genes were seen to be significantly altered in the primary visual cortex using the described cut-offs (see Fig. 3 and Table 1). Several systems were identified as altered in the primary visual cortex and linked with DLB most notably in cellular signalling, synaptic transmission, and vesicle transport (see Additional file 7: Table S7). However, GO-term analysis specifically identified GABAergic changes as being prominent (see Additional file 7: Table S7). For example, the mRNAs encoding neuropeptide precursor proteins such as proenkephalin (PENK), tachykinin (TAC1) and prodynorphin (PDYN) transcripts (see Table 1) were altered. These neuropeptides are primarily expressed by specific interneurone populations which are also GABAergic. This suggests there may be GABAergic dysfunction in the primary visual cortex in DLB, a hypothesis supported by the presence of other GABAergic markers in this patient group, most notably GAD2 (GAD65) and SLC32A1 and therefore we focussed on the GABAergic system. Using GAD65/67 to stain GABAergic cells, no alteration in total counts of cells was seen in the cortex of DLB or $\mathrm{AD}$ patients when compared to control in either primary visual (ANOVA: $\mathrm{F}[2,23]=0.389, p=0.682$ ) or secondary visual cortices (ANOVA: $\mathrm{F}[2,23]=1.184, p=0.186$; see Additional file 8: Table S4). This was paralleled by an absence of any change in GAD1 mRNA transcripts in DLB relative to control, although a slight but significant reduction GAD1 mRNA was seen in AD compared to control ( $p=0.0337$, uncorrected; Table 2$)$, though $\mathrm{AD}$ and DLB groups were comparable. Similarly, there was no alteration in GAD65 or GAD67 protein determined by western blotting in either DLB or AD compared to control (see Table 2) suggesting that GABAergic neurones are still present in normal numbers but dysfunctional.

\section{Protein}

To explore the possibility that GABAergic neurones had either degenerated or were dysfunctional in specific neuronal subtypes, numbers of calcium binding protein containing neurones were quantified to determine if cell loss was selective. We studied the levels of parvalbumin (PVALB, mRNA; PVALB, protein), a marker of the fast spiking basket and chandelier neurones that provide major inhibitory inputs onto soma and axons of 


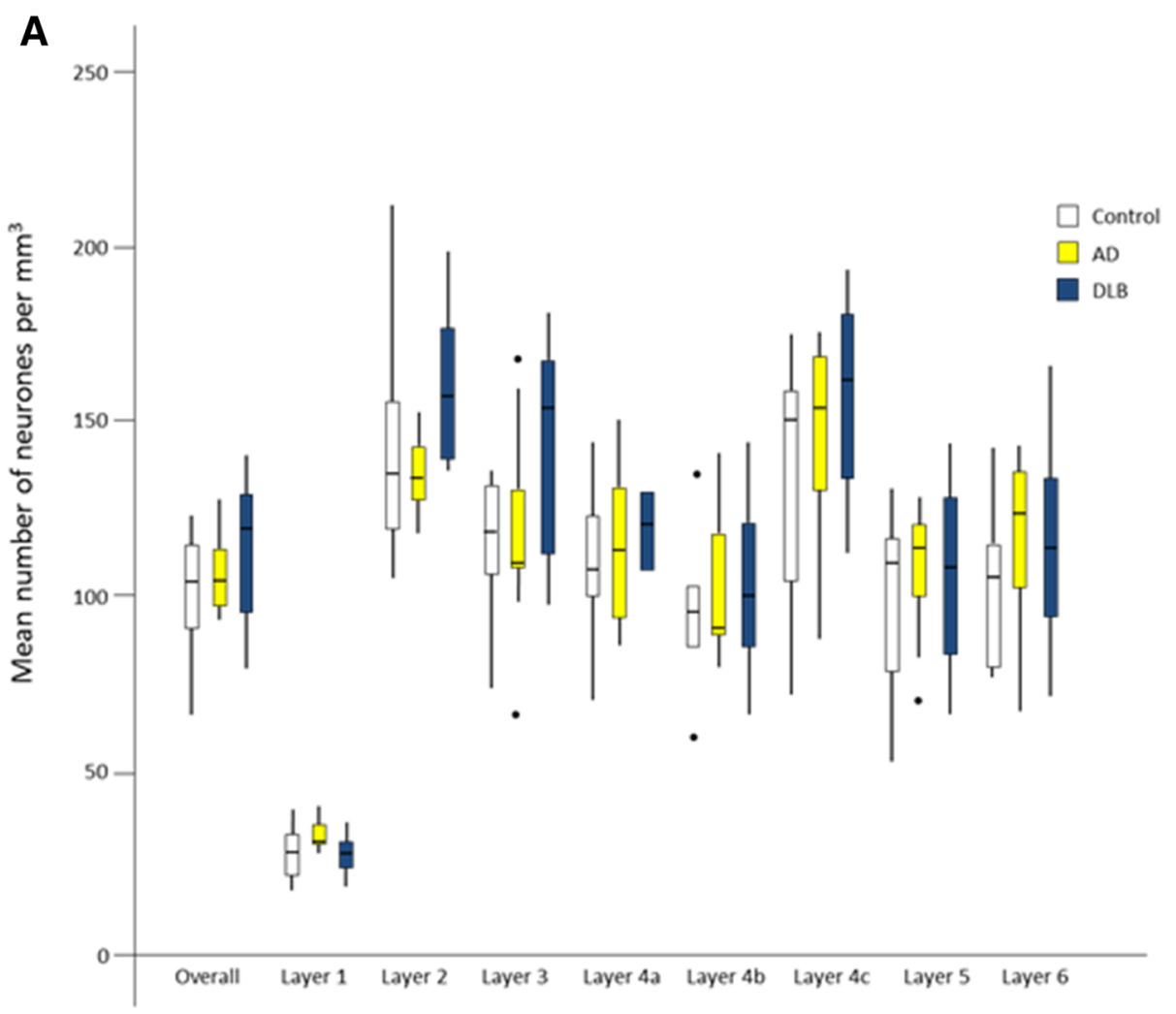

B

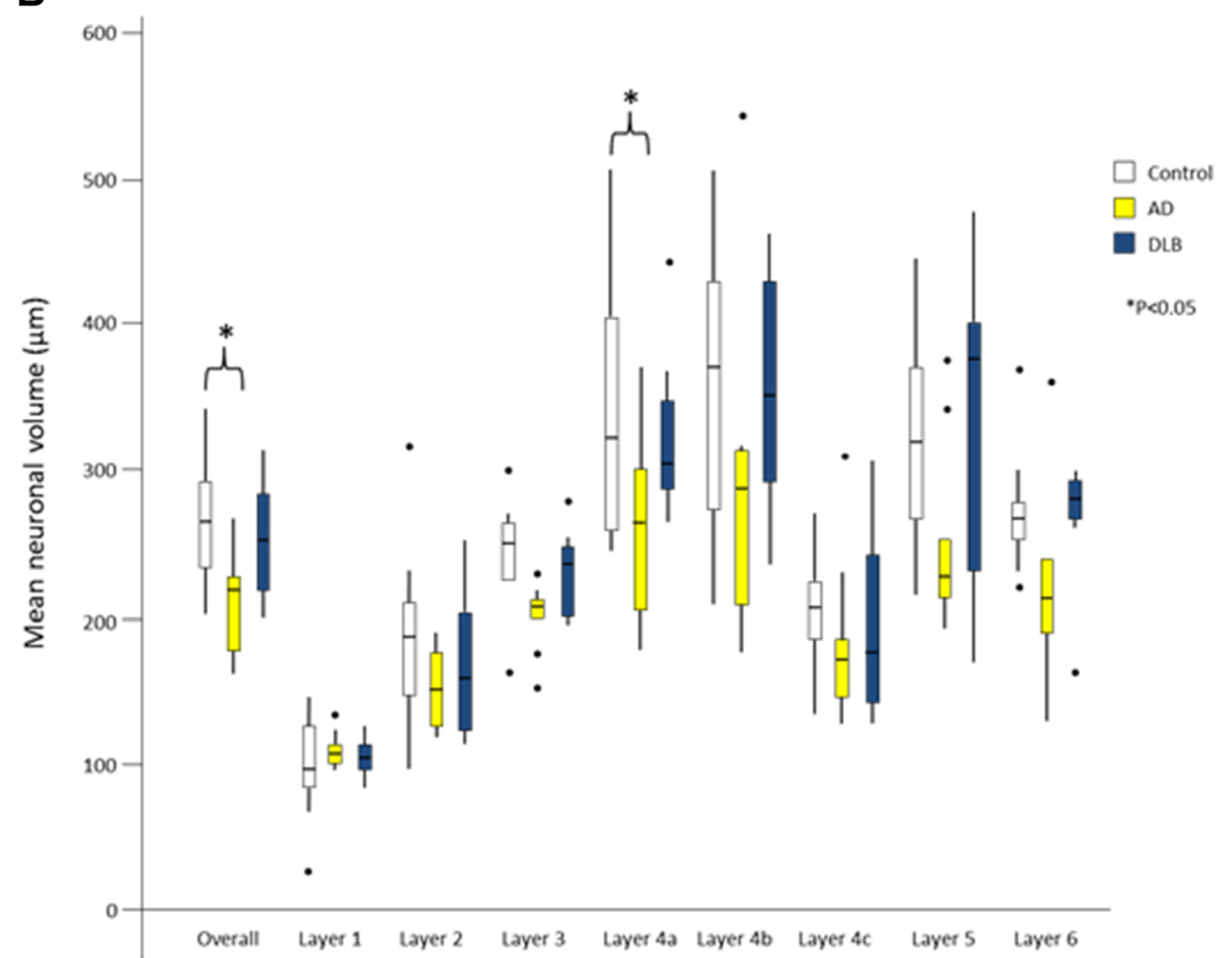

Fig. 2 (See legend on next page.) 
(See figure on previous page.)

Fig. 2 Neuronal density (a) and Neuronal volume (b) within the individual layers and across all layers (overall) of primary visual cortex in dementia with Lewy bodies (DLB) and Alzheimer's disease (AD). a Stereological analysis using the optical disector was used in primary visual cortex to determine neuronal density. No change in neuronal density was seen in DLB or AD. Boxplots show the median and quartile range with whiskers as the highest and lowest values within $1.5 \mathrm{x}$ the interquartile range. $\bullet$, outlier points. $\mathbf{b}$ No overall reduction in neuronal volume was observed in DLB compared to elderly controls. There was a significant overall reduction in neuronal volume in AD compared to control and specifically a significant reduction in neuronal volume in layer $4 \mathrm{a}$ in $\mathrm{AD}(P<0.05)$. Boxplots show the median and quartile range with whiskers as the highest and lowest values within $1.5 \times$ the interquartile range. $\bullet$, outlier points. $t, P<0.05$

pyramidal neurones. PVALB mRNA was significantly reduced in DLB ( $p=0.0035$, uncorrected) compared to control but was also significantly increased in $\mathrm{AD}(p=$ 0.0002 , uncorrected) (Table 2) compared to control. These changes in PVALB mRNA were reflected by changes in PVALB protein with a reduction of approximately $15 \%$ in DLB ( $p=0.033$, uncorrected) and an increase in AD of approximately $25 \%(p=0.0005$, uncorrected) when compared to control. Given the absence of any reduction in overall GABAergic neurones, parvalbumin, D-28 calbindin and calretinin neuronal density in the primary visual cortex was investigated using stereological methods. No significant change in the density of these neuronal markers in either DLB or AD were seen (see Fig. 4) suggesting that whilst the neurones may show altered marker profiles, their density is unchanged. To further investigate this, altered marker profile protein levels for other neuropeptides within the primary visual cortex in DLB were assessed. Neuropeptide Y levels, when compared to control, were not significantly increased on ELISA analysis in DLB by $(p=0.22$, uncorrected) and in AD NPY was increased by approximately $20 \%$ compared to control ( $p=0.027$, uncorrected) (see Table 2). Somatostatin levels in primary visual cortex were unchanged in $\mathrm{DLB}(p=0.40$, uncorrected) or in $\mathrm{AD}(p=$ 0.09 , uncorrected) compared to control.

Since previous functional studies have suggested either decreased inhibition or increased excitatory drive in the primary visual cortex [59] and in light of the findings implicating GABAergic neurones based on the microarray data, we explored the possibility that altered inhibition was present. To determine if the neuropeptide changes were associated with alterations in other GABAergic markers, levels of several proteins involved in GABA neurotransmission were determined. The GABAergic post-synaptic marker GABARAP involved in GABA (A) receptor clustering/transport [60] showed reduced expression of the $17 \mathrm{kDa}$ GABARAP isoform of approximately $40 \%(P<0.001$, uncorrected $)$ when compared to control and of the $14 \mathrm{kDa}$ GABARAP isoform of approximately $30 \%(P<0.001$, uncorrected $)$ in $\mathrm{DLB}$; in $\mathrm{AD}$ the $17 \mathrm{kDa}$ isoform was reduced to a lesser extent by about $15 \%(P<0.001$, uncorrected $)$ and the $14 \mathrm{kDa}$ isoform by $20 \%(P<0.001$, uncorrected $)$ when compared to controls (see Table 2). The GABA motor protein Kif5A showed a trend towards reduction in DLB compared to control ( $p=0.06$, uncorrected), but no change in AD. Gephyrin, a post synaptic GABA-A associated protein which anchors GABAergic and glycinergic receptors to the post-synaptic cytoskeleton [61] showed a significant reduction of approximately $25 \%$ in DLB compared to control $(P<0.001$, uncorrected $)$ and in $\mathrm{AD}$ a reduction of about $20 \%(P<0.0001$, uncorrected). Using ionotropic GABA A1 receptor subunit as an additional marker of receptor activity, showed no change in either DLB or AD when compared to control (see Table 2).

Since alterations of GABAergic activity may lead to altered net excitation, a series of glutamatergic synaptic markers were assessed (see Table 2). Using an antiVGlut1 (SLC17A7) antibody as a marker of cortical input into the primary visual cortex, we demonstrated bands from $59-61 \mathrm{kDa}$, reflecting VGlut1 isoforms ranging from 59.3 to $61.3 \mathrm{kDa}$. DLB cases were not significantly different from controls in VGlut1 isoform 1 $(61.3 \mathrm{kDa} ; p=0.14)$, and AD cases were unchanged ( $p=$ 0.08 , uncorrected). DLB cases were also not significantly different from controls in VGlut1 isoform $2(59.3 \mathrm{kDa}$; $p=0.72)$ and $\mathrm{AD}$ cases were also not changed compared to controls $(p=0.78)$. Similarly the metabotropic glutamate receptor mGluR1 was also unaltered in DLB and we saw no loss of ionotropic AMPA glutamate receptor (GluR1/GRIA1) mRNA. As a marker of neural activity we observed a selective reduction in BDNF mRNA in the primary visual cortex in DLB cases when compared to control $(P<0.05$, uncorrected; Table 2$)$ but were unable to detect BDNF protein in any samples using a specific ELISA. Whilst variable, there was no change of the postsynaptic excitatory scaffold protein DLG4 (PSD-95) mRNA in DLB compared to control, and in AD this reduction was significant compared to control $(P<0.05$, uncorrected; see Table 2). PSD95 protein determination, however, showed a marked 50 \% decrease in DLB compared to controls $(p=0.0002$, uncorrected), whilst AD cases showed no change in PSD95 $(p=0.96)$ in primary visual cortex compared to control. In line with PSD-95 findings, we identified a reduction of $43 \%$ of the growth cone marker GAP43 ( $p=0.0005$, uncorrected), whilst 


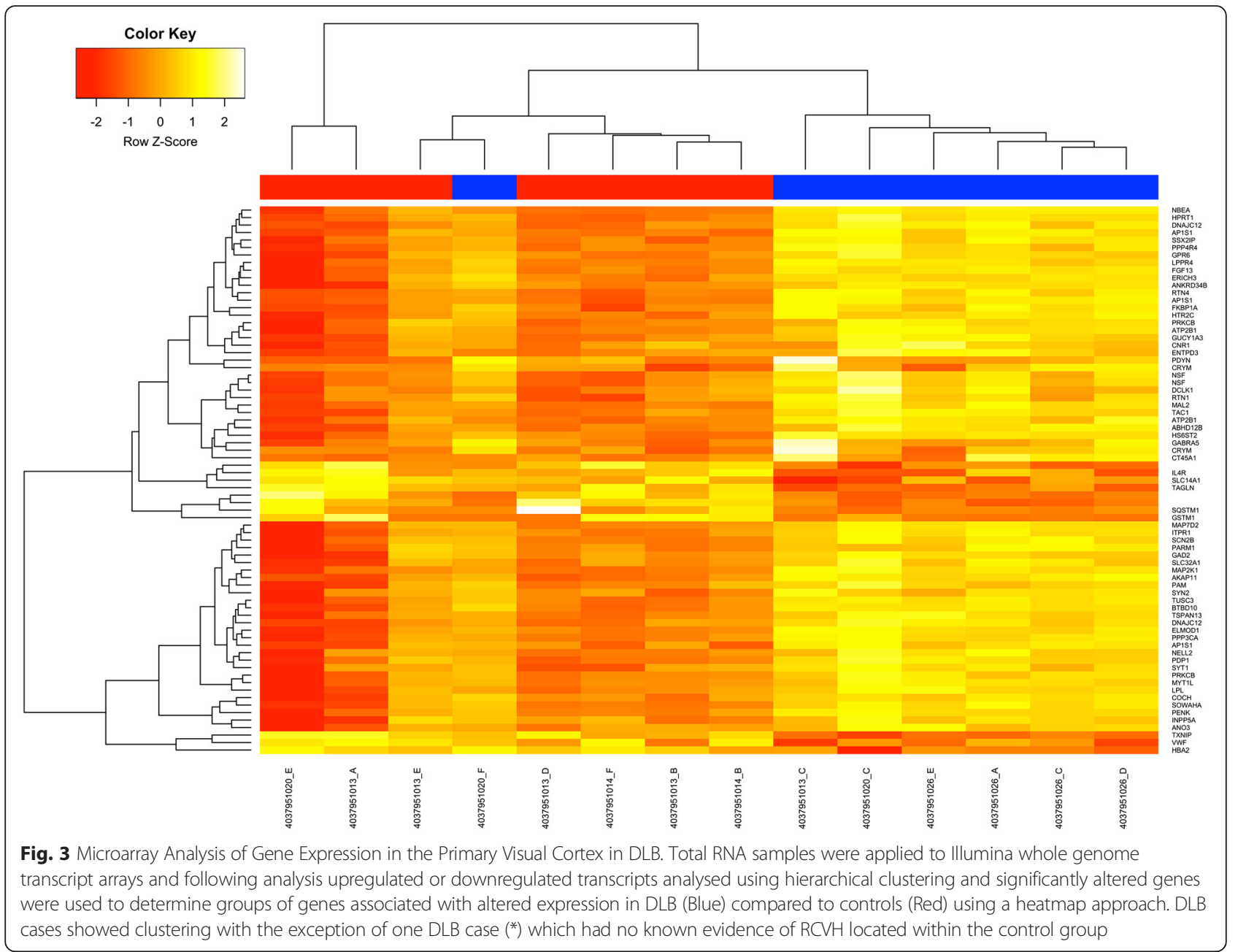

AD cases showed no change $(p=0.11)$ when compared to control in DLB primary visual cortex. As markers of synaptic neurotransmission, we determined synaptophy$\sin$ as a marker for presynaptic vesicular membranes and SNAP25 levels as a marker of presynaptic vesicles. Synaptophysin showed a marked and significant $44 \%$ decrease compared to control in DLB cases $(P<0.00001$, uncorrected) and also a lesser $22 \%$ decrease in AD cases compared to control ( $p=0.01$, uncorrected). DLB cases, however, showed no change in SNAP25 expression compared to controls $(p=0.43)$, and similarly AD cases also showed no significant change in SNAP25 expression compared to controls $(p=0.13)$ indicating general exocytosis was unaltered.

\section{Discussion}

Visual hallucinations have a complex aetiology with the potential involvement of multiple systems including the eye, primary visual cortex, and higher order brain regions $[5,6]$. This study showed an absence of demonstrable neuropathological changes in primary visual cortex with no significant evidence of Lewy body- or AD- pathology or neuronal change in DLB, and similar to other studies [21], with the presence of mild pathology in adjacent occipital cortical regions. Recent evidence suggests that occipital involvement may be seen in individuals with $\mathrm{PD}$ with concomitant $\mathrm{AD}$ pathology, and also in cases with a clinical presentation of $\mathrm{AD}$ with the presence of Lewy bodies, although the presence of $\alpha$-synuclein pathology within the primary visual cortex was not noted specifically [62]. This may indicate that the primary visual cortex could indeed be affected by pathology in DLB, if there are high levels of coexisting AD pathology, although in the current study such cases were not included. Whilst some studies show an absence of laterality in structural MRI in DLB [63, 64], some studies show lateralised changes [19], and therefore the current study, since it only determined cell counts and pathology in one hemisphere, may miss any unilateral changes. While the stereological approach used investigated all layers of the primay visual cortex, there may be a potential bias towards estimating pyramidal neurone 
Table 1 Microarray analysis of Gene Expression in Primary Visual Cortex in DLB

\begin{tabular}{|c|c|c|c|}
\hline symbol & name & $\log \mathrm{FC}$ & adj.P.Val \\
\hline PENK & proenkephalin & 2.328 & 0.003 \\
\hline $\mathrm{HTR} 2 \mathrm{C}$ & 5-hydroxytryptamine (serotonin) receptor 2C, G protein-coupled & 2.029 & 0.001 \\
\hline SOWAHA & sosondowah ankyrin repeat domain family member $\mathrm{A}$ & 1.588 & 0.001 \\
\hline MAL2 & mal, T-cell differentiation protein 2 (gene/pseudogene) & 1.583 & 0.001 \\
\hline TAC1 & tachykinin, precursor & 1.537 & 0.003 \\
\hline FKBP1A & FK506 binding protein $1 \mathrm{~A}, 12 \mathrm{kDa}$ & 1.527 & 0.001 \\
\hline PRKCB & protein kinase $C$, beta & 1.489 & 0.003 \\
\hline ENTPD3 & ectonucleoside triphosphate diphosphohydrolase 3 & 1.452 & 0.022 \\
\hline ELMOD1 & ELMO/CED-12 domain containing 1 & 1.436 & 0.001 \\
\hline RTN4 & reticulon 4 & 1.409 & 0.001 \\
\hline ATP2B1 & ATPase, Ca++ transporting, plasma membrane 1 & 1.388 & 0.003 \\
\hline GPR6 & G protein-coupled receptor 6 & 1.387 & 0.003 \\
\hline PPP3CA & protein phosphatase 3 , catalytic subunit, alpha isozyme & 1.372 & 0.002 \\
\hline $\mathrm{COCH}$ & cochlin & 1.355 & 0.005 \\
\hline CRYM & crystallin, mu & 1.334 & 0.035 \\
\hline SLC32A1 & solute carrier family 32 (GABA transporter), member 1 & 1.329 & 0.010 \\
\hline PRKCB & protein kinase $C$, beta & 1.318 & 0.006 \\
\hline AP1S1 & adaptor-related protein complex 1 , sigma 1 subunit & 1.297 & 0.001 \\
\hline GUCY1A3 & guanylate cyclase 1 , soluble, alpha 3 & 1.285 & 0.004 \\
\hline FGF13 & fibroblast growth factor 13 & 1.265 & 0.001 \\
\hline SYT1 & synaptotagmin I & 1.243 & 0.009 \\
\hline GABRA5 & gamma-aminobutyric acid (GABA) A receptor, alpha 5 & 1.236 & 0.020 \\
\hline $\mathrm{CT} 45 \mathrm{~A} 1$ & cancer/testis antigen family 45 , member $\mathrm{A} 1$ & 1.230 & 0.047 \\
\hline LPL & lipoprotein lipase & 1.226 & 0.007 \\
\hline MAP7D2 & MAP7 domain containing 2 & 1.199 & 0.004 \\
\hline PDYN & prodynorphin & 1.196 & 0.046 \\
\hline TSPAN13 & tetraspanin 13 & 1.182 & 0.003 \\
\hline PDP1 & pyruvate dehyrogenase phosphatase catalytic subunit 1 & 1.180 & 0.003 \\
\hline TUSC3 & tumor suppressor candidate 3 & 1.164 & 0.001 \\
\hline NELL2 & NEL-like 2 (chicken) & 1.161 & 0.010 \\
\hline SSX2IP & synovial sarcoma, $\mathrm{X}$ breakpoint 2 interacting protein & 1.153 & 0.001 \\
\hline SYN2 & synapsin II & 1.151 & 0.009 \\
\hline ITPR1 & inositol 1,4,5-trisphosphate receptor, type 1 & 1.150 & 0.003 \\
\hline AP1S1 & adaptor-related protein complex 1 , sigma 1 subunit & 1.147 & 0.001 \\
\hline AP1S1 & adaptor-related protein complex 1 , sigma 1 subunit & 1.139 & 0.003 \\
\hline GAD2 & glutamate decarboxylase 2 (65 kDa) & 1.132 & 0.014 \\
\hline PPP4R4 & protein phosphatase 4 , regulatory subunit 4 & 1.125 & 0.002 \\
\hline ANKRD34B & ankyrin repeat domain $34 \mathrm{~B}$ & 1.123 & 0.003 \\
\hline ATP2B1 & ATPase, Ca++ transporting, plasma membrane 1 & 1.117 & 0.005 \\
\hline NSF & $\mathrm{N}$-ethylmaleimide-sensitive factor & 1.112 & 0.002 \\
\hline BTBD10 & BTB (POZ) domain containing 10 & 1.105 & 0.001 \\
\hline SCN2B & sodium channel, voltage-gated, type II, beta subunit & 1.099 & 0.003 \\
\hline NSF & N-ethylmaleimide-sensitive factor & 1.087 & 0.002 \\
\hline RTN1 & reticulon 1 & 1.083 & 0.005 \\
\hline
\end{tabular}


Table 1 Microarray analysis of Gene Expression in Primary Visual Cortex in DLB (Continued)

\begin{tabular}{|c|c|c|c|}
\hline PARM1 & prostate androgen-regulated mucin-like protein 1 & 1.078 & 0.010 \\
\hline ANO3 & anoctamin 3 & 1.076 & 0.029 \\
\hline CRYM & crystallin, mu & 1.072 & 0.030 \\
\hline CNR1 & cannabinoid receptor 1 (brain) & 1.072 & 0.039 \\
\hline LPPR4 & lipid phosphate phosphatase-related protein type 4 & 1.069 & 0.001 \\
\hline MAP2K1 & mitogen-activated protein kinase kinase 1 & 1.065 & 0.001 \\
\hline AKAP11 & A kinase (PRKA) anchor protein 11 & 1.054 & 0.001 \\
\hline INPP5A & inositol polyphosphate-5-phosphatase, $40 \mathrm{kDa}$ & 1.043 & 0.027 \\
\hline PAM & peptidylglycine alpha-amidating monooxygenase & 1.041 & 0.006 \\
\hline $\mathrm{ERICH} 3$ & glutamate-rich 3 & 1.041 & 0.003 \\
\hline HPRT1 & hypoxanthine phosphoribosyltransferase 1 & 1.030 & 0.001 \\
\hline ABHD12B & abhydrolase domain containing $12 \mathrm{~B}$ & 1.025 & 0.002 \\
\hline NBEA & neurobeachin & 1.024 & 0.002 \\
\hline HS6ST2 & heparan sulfate 6-O-sulfotransferase 2 & 1.021 & 0.001 \\
\hline DNAJC12 & DnaJ (Hsp40) homolog, subfamily C, member 12 & 1.011 & 0.001 \\
\hline DCLK1 & doublecortin-like kinase 1 & 1.010 & 0.018 \\
\hline DNAJC12 & DnaJ (Hsp40) homolog, subfamily C, member 12 & 1.000 & 0.002 \\
\hline SLC14A1 & solute carrier family 14 (urea transporter), member 1 & -1.020 & 0.033 \\
\hline IL4R & interleukin 4 receptor & -1.071 & 0.039 \\
\hline GSTM1 & glutathione S-transferase mu 1 & -1.090 & 0.025 \\
\hline SQSTM1 & sequestosome 1 & -1.098 & 0.044 \\
\hline WF & von Willebrand factor & -1.101 & 0.039 \\
\hline NPIPB4 & nuclear pore complex interacting protein family, member B4 & -1.141 & 0.004 \\
\hline TAGLN & transgelin & -1.178 & 0.004 \\
\hline LOC285407 & asparagine-linked glycosylation 1 homolog pseudogene & -1.184 & 0.001 \\
\hline TMEM137 & TMEM137 & -1.244 & 0.002 \\
\hline HBA2 & hemoglobin, alpha 2 & -1.382 & 0.043 \\
\hline TXNIP & thioredoxin interacting protein & -1.522 & 0.003 \\
\hline
\end{tabular}

Listing of significantly altered genes $( \pm 2.0$ fold change, $\mathrm{FDR}<0.05)$ from the whole genome microarray are displayed along with their average fold change. Neuropeptide/GABAergic interneurone markers are highlighted in bold

changes since pyramidal neurones can be more readily identified in Nissl stained sections compared to small interneurones. The lack of any changes in any cortical layers enriched for pyramidal neurones in DLB would suggest no major alterations in pyramidal neurones due to oversampling. Additionally, the results from directly determining interneurone density changes which also appear unchanged in DLB (Fig. 4) suggest that any possible bias towards sampling large pyramidal neurones in the current study is likely to be small. The current results, however, suggest that occipital hypoperfusion and hypometabolism seen in conjunction with $\mathrm{RCVH}$ is not due to neurodegeneration within the primary visual cortex. Similar findings of reduced perfusion and metabolism including within occipital cortex in $\mathrm{PD}$ and in relation to visual hallucinations may indicate that the findings here in DLB may also relate to PD, although this will require further investigation [65-67]. In relation to the findings in $\mathrm{AD}$, however, the presence of major pathology and also of neuronal atrophy, may indicate that the primary visual cortex is simply less responsive to stimulation, and consequently $\mathrm{RCVH}$ in $\mathrm{AD}$ are not common findings due to neurodegeneration.

Because of the absence of pathology in DLB, we used a transcriptomic approach to determine the gene expression changes that may underpin possible changes in the primary visual cortex. The current findings indicate there is an alteration in the profile of several genes and changes in GABA and neuropeptide markers indicate changes in the interneurone pool. Whilst the microarray findings show 
Table 2 GABAergic Interneurone Markers and Glutamatergic Markers in the Primary Visual Cortex in Dementia with Lewy Bodies and Alzheimer's disease

\begin{tabular}{|c|c|c|c|}
\hline Protein/mRNA & Control & DLB & $A D$ \\
\hline GAD1 mRNA & $1.46 \pm 0.62$ & $0.86 \pm 0.22$ & $0.62 \pm 0.15^{*}$ \\
\hline GAD67 protein & $0.85 \pm 0.21$ & $0.85 \pm 0.16$ & $0.72 \pm 0.13$ \\
\hline GAD65 protein & $1.12 \pm 0.26$ & $1.16 \pm 0.26$ & $0.91 \pm 0.15$ \\
\hline PVALB mRNA & $1.59 \pm 0.47$ & $0.87 \pm 0.24 \dagger$ & $3.51 \pm 0.55^{* *}$ \\
\hline PVALB protein & $0.70 \pm 0.22$ & $0.61 \pm 0.25^{*}$ & $0.87 \pm 0.25^{* * *}$ \\
\hline $\mathrm{NPY} \mathrm{pg} / \mathrm{mg}$ & $5.71 \pm 1.95$ & $6.63 \pm 1.62$ & $7.39 \pm 1.52^{*}$ \\
\hline SST ng/mg & $0.42 \pm 0.18$ & $0.48 \pm 0.15$ & $0.60 \pm 0.27 \dagger$ \\
\hline GABARAP-17 kDa & $1.56 \pm 0.28$ & $0.91 \pm 0.19^{* * *}$ & $1.29 \pm 0.28^{* *}$ \\
\hline GABARAP-14 kDa & $1.47 \pm 0.27$ & $0.99 \pm 0.14^{* * *}$ & $1.15 \pm 0.26^{* *}$ \\
\hline Gephyrin & $1.13 \pm 0.27$ & $0.84 \pm 0.08^{* *}$ & $0.67 \pm 0.09^{* *}$ \\
\hline GABA A a1 & $0.75 \pm 0.30$ & $0.82 \pm 0.26$ & $0.83 \pm 0.39$ \\
\hline Kif5A & $0.95 \pm 0.58$ & $0.51 \pm 0.10 \dagger$ & $0.90 \pm 0.09$ \\
\hline GRIN2A mRNA & $1.44 \pm 0.79$ & $0.70 \pm 0.16$ & $0.89 \pm 0.31$ \\
\hline GluR1/GRIA1 protein & $0.94 \pm 0.13$ & $0.89 \pm 0.33$ & NT \\
\hline vGlut1(SLC17A7) protein 61.3 kDa & $1.20 \pm 0.24$ & $1.04 \pm 0.18$ & $0.91 \pm 0.11 \dagger$ \\
\hline vGlut1(SLC17A7) protein 59.3 kDa & $0.90 \pm 0.13$ & $0.87 \pm 0.1$ & $0.90 \pm 0.12$ \\
\hline PSD95 (DLG4) mRNA & $3.33 \pm 1.14$ & $1.80 \pm 0.61 \dagger$ & $0.83 \pm 0.26^{*}$ \\
\hline PSD-95 protein & $1.25 \pm 0.22$ & $0.62 \pm 0.19^{* * *}$ & $1.24 \pm 0.28$ \\
\hline GAP43 protein & $1.25 \pm 0.45$ & $0.71 \pm 0.22^{* * *}$ & $1.08 \pm 0.16$ \\
\hline BDNF MRNA & $0.70 \pm 0.16$ & $0.39 \pm 0.14^{*}$ & $0.71 \pm 0.48$ \\
\hline BDNF protein & ND & ND & ND \\
\hline Synaptophysin (SYP) mRNA & $1.76 \pm 0.72$ & $0.89 \pm 0.22$ & $2.69 \pm 0.80$ \\
\hline Synaptophysin protein & $0.96 \pm 0.25$ & $0.54 \pm 0.09^{* * *}$ & $0.720 .16^{*}$ \\
\hline SNAP25 mRNA & $1.27 \pm 0.30$ & $0.88 \pm 0.23$ & $0.83 \pm 0.25$ \\
\hline SNAP25 protein & $1.10 \pm 0.28$ & $0.99 \pm 0.13$ & $1.10 \pm 0.17$ \\
\hline
\end{tabular}

Relative expression levels (+/- SEM) for GABAergic interneurone marker transcripts and proteins in control, DLB and AD primary visual cortex were determined using validated Taqman assays by real time PCR and proteins determined using western blotting of the appropriate protein band with relative expression levels being normalised to GAPDH mRNA or protein. Values represent the $2^{-\triangle \Delta C T}$ value for mRNA and protein/GAPDH for the specific protein. NPY and SST levels were determined using specific sandwich ELISA. Uncorrected $p$ values are presented with, ${ }^{*}, P<0.05$ relative to control; ${ }^{* *}, P<0.01$ relative to control; ${ }^{* * *}, P<0.005$ relative to control; $t, P<0.1,>0.05$. BDNF protein was not detected (ND) in any samples using an ELISA method NT Not tested

synaptic, and specifically GABAergic, changes, the major interneurone population is still intact based on the density of calcium binding protein positive neurones present, underscoring that dysfunction rather than degeneration occurs in the primary visual cortex in DLB. We have, however, not shown the presence of major changes in the levels of these calcium binding proteins and so it is difficult to determine if one specific group of interneurons is affected, although the microarray data appears to indicate that several groups of interneurons are affected, particularly enkephalinergic and tachykininergic neurones (see Table 1). Although the transcriptomic and morphological changes in the primary visual cortex point towards dysfunction, the underlying changes in neurotransmission that regulate this region require definition and synaptic changes associated with both inhibitory interneurones and excitatory neurones are present. Since $\mathrm{RCVH}$ are a very common feature of DLB (this study had access to only one case of DLB without RCVH; see Fig. 3) our findings may relate to an intrinsic property of the primary visual cortex in DLB, since while we used an AD group to look at degenerative changes, $\mathrm{RCVH}$ are not common in $\mathrm{AD}$. The changes we have identified may therefore be a unique feature of DLB, rather than simply due to RCVH. The location of the individual case of DLB without RCVH in the control cluster following microarray would though indicate that the microarray findings may be linked to RCVH. Additional studies with cases of DLB where there is a well documented absence of hallucinations will be required to resolve this issue.

The current transcriptomic analysis points to altered synaptic function and specifically GABA dysfunction in 


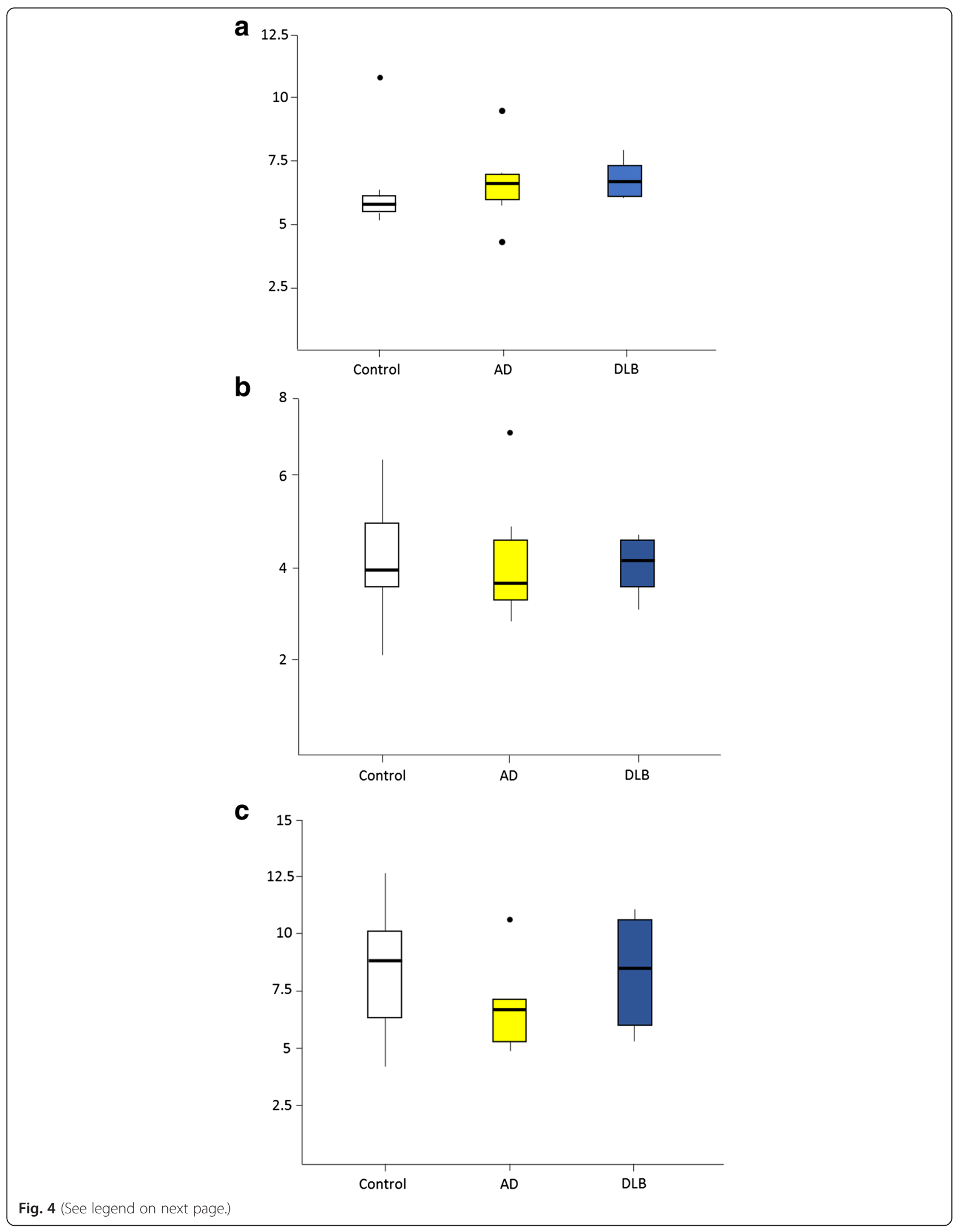


(See figure on previous page.)

Fig. 4 Analysis of Interneurone Populations in the Primary Visual Cortex in Dementia with Lewy Bodies and Alzheimer's Disease. Immunohistochemistry

for a) parvalbumin, b) calretinin, and c) calbindin was used to label specific interneurone populations in the primary visual cortex and neuronal density

determined. No significant loss of interneurone populations was observed in either DLB or AD in the primary visual cortex. ${ }^{0}$, outlier points

DLB (see Additional file 7: Table S7). The changes in GABAergic interneurones suggest that there may be parallels with the changes seen in the primary visual cortex following reduced visual input in animals $[68,69]$. Here, reduced input leads typically to functional changes in inhibitory interneurones with a reduced expression of parvalbumin in fast spiking interneurones [70]. There are also changes in the primary visual cortex following reduced stimulation with an increased turnover of synaptic boutons of interneurones both acutely and chronically [71, 72]. While much of this work has been conducted in the mouse, primate work also suggests a loss of GABAergic interneurone function following decreased input and this may occur acutely in man [73]. The hypometabolism seen in DLB in the medial occipital lobe in DLB may also relate to decreased GABA function since, studies support the possibility that blood flow is reduced with reduced GABA activity [74-76], although studies also indicate that increasing GABA levels causes reduced blood flow in younger subjects [77]. The reduced expression of GABAergic markers such as gephyrin and GABARAP may be an indication of the eye pathology frequently found in DLB patients and in ageing $[13,23]$. DLB patients frequently show visuoperceptual impairments and the presence of severe ocular pathology may reduce input to the primary visual cortex [13, 78] although the presence of eye disease is not a universal feature of DLB (Additional file 1: Table S1 and Additional file 3: Table S2). Conversely, environmental enrichment in mice leads to enhanced BDNF expression in the primary visual cortex [79], which contrasts with the potentially decreased BDNF mRNA expression seen in DLB cases in the current study (see Table 2). Visual input regulates the expression of BDNF mRNA [80] in glutamatergic neurones with reduction of BDNF leading to altered GABAergic transmission [81]. Changes within the eye [82], an absence of retinal thinning [83] and an absence of pathology within the lateral geniculate nucleus [84] indicate that not all DLB patients have eye disease (see Additional file 1: Table S1 and Additional file 3: Table S2) and this suggests that RCVH therefore do not require pathology within the eye or proximal visual system to occur or for hypometabolism and hypoperfusion to be present in the primary visual cortex. It is possible therefore that the findings indicate a stereotyped response of the primary visual cortex in an attempt to increase excitation by reducing post synaptic inhibitory synapses and decreasing inhibition, and would support the suggestion of decreased inhibition as a factor in RCVH in DLB [85]. Alternatively, the hypoperfusion and hypometabolism seen in the primary visual cortex in DLB may be due to lesions in other brain regions. Increased perfusion following cholinesterase inhibitor treatment occurs in lateral and posterior occipital cortex in DLB, and this may indicate that pathology within the basal forebrain cholinergic system may be in part responsible for the reduced perfusion observed [86]. Whilst there is a relatively selective reduction in perfusion of the primary visual cortex in DLB compared with $\mathrm{AD}$, this is on a background of generalised hypometabolism involving temporal, parietal, and occipital regions when compared to elderly cognitively normal individuals [11, 87], and therefore other brain regions may potentially influence the perfusion and metabolism within the primary visual cortex.

This study indicates the presence of altered GABAergic synapses in DLB. Previous investigations of synaptic markers in the primary visual cortex in DLB have suggested loss of SNAP25 and syntaxin which we did not observe in the current study. In prior studies this may be due to the use of indirect ELISA determination with potential cross reactivity of antibodies, which would not be seen with our more robust western blotting approach [88]. Demographic factors, including longer post mortem interval and lower brain $\mathrm{pH}$ (indicating poor agonal state), are known to negatively affect synaptic protein levels [89] and will have influenced previous investigations. Our results are more in line with preserved function that would be seen with preserved SNAP25 levels, which is essential for neurotransmitter exocytosis [90]. Studies in other brain regions (e.g. frontal cortex) in DLB have shown relatively preserved synaptic markers [91, 92], which would correlate with the selective loss of certain marker proteins, rather than a generalised loss of synapses per se. The current results suggest connectivity is selectively altered in the primary visual cortex of DLB, with a change in specific synaptic marker proteins and genes, for example PSD95, compared to the atrophy associated changes seen with AD. PSD95 is specifically associated with the excitatory post-synaptic membrane [93]. Whilst the major input to the primary visual cortex from the lateral geniculate nucleus appears normal [84], input from adjacent visual cortical areas (secondary visual cortex, etc.) and through secondary visual pathways via the pulvinar occur, and so reductions in PSD95 may represent such defects. Using VGlut1 as a marker of 
cortico-cortical connections, we observed no significant reductions in VGlut1 in DLB but observed reductions in VGlut1 in AD where there was a general reduction along with atrophy in excitatory neurones (Fig. 2) due to pathology [94]. This would indicate that intrinsic and major cortical glutamatergic synapses are not lost in DLB but that changes within glutamatergic neurones may represent the observed changes in PSD-95. This supports the concept of reduced visual system input to the primary visual cortex as being part of the process of generation of RCVH in DLB as with other primary visual system lesions [5] and that "bottom up" changes are important in $\mathrm{RCVH}$ as has been noted for PD [95].

The changes in GABA neurotransmission may have a clinical correlate within the symptomatology of RCVH in DLB. Altered GABA neurotransmission may be observed as a change in the excitability of pyramidal neurones where in DLB, the use of transcranial magnetic stimulation of the occipital cortex (occiput) is correlated with increased generation of $\mathrm{RCVH}$ like phosphenes [96] possibly as a result of decreased inhibition. Reduced levels of parvalbumin, such as seen in this study, have been suggested to cause altered cortical gamma oscillations whereby the gain and modulation of firing of pyramidal neurones is affected [97, 98]. Desynchronisation of pyramidal neurones in the primary visual cortex and net increased excitability due to reduced inhibition may therefore lead abnormal outflow to higher order visual areas which appear to show changes in DLB [78] resulting in $\mathrm{RCVH}$.

The presence of reduced visual input into the primary visual cortex in DLB, whilst being part of the aetiology of $\mathrm{RCVH}$, does suggest that further changes must contribute to RCVH. For example, RCVH do not necessarily occur in blind individuals, and this suggests that other pathological or biochemical changes are required in order to result in $\mathrm{RCVH}$ [78]. Considerable attention has focussed on changes in temporal lobe structures in DLB and also PD in relation to visual hallucinations [7, 78]. Pathological correlates have indicated that temporal lobe Lewy bodies correlate with the presence of $\mathrm{RCVH}$ [33] and that, in PD, elevated Lewy body density in the basolateral nucleus of the amygdala and temporal lobe associate with RCVH [24, 34]. Structurally, however, there is relative preservation of the temporal lobe in DLB [17], although this may not be the case in PD with RCVH [99]. This is accompanied in DLB with decreased connectivity of the temporal lobe $[78,100]$ and perfusion deficits, specifically in the ventral occipitotemporal junction following visual stimulation of DLB patients with frequent and more severe $\mathrm{RCVH}$ [63].

Our results therefore show that, in the absence of major pathological changes in the primary visual cortex in DLB, there are functional changes associated with GABAergic neurones. This may reflect a change to the visual input due to reduced visual acuity as a consequence of age related changes in the eye. These changes lead to an inhibitory/excitatory imbalance in the primary visual cortex and altered perception of visual stimuli due to changes in association cortex. One possibility is that by treating major eye disease where it is present, by opting for a more proactive approach, RCVH may be reduced [101]. Alternatively, modulation of GABAergic inhibition using selective modulators of specific GABA receptors might be feasible to determine if $\mathrm{RCVH}$ are reduced in small scale clinical trials, using appropriate scales for estimating $\mathrm{RCVH}$ frequency and severity $[63,78]$. Modulation of glutamatergic signalling may also be of benefit, perhaps by acting on group II metabotropic glutamatergic receptors, again in small scale experimental studies using appropriate scoring systems for $\mathrm{RCVH}$ [102]. It may therefore be possible to ameliorate the recurrent visual hallucinations perceived by DLB patients using appropriate interventions.

\section{Additional files}

Additional file 1: Table S1. Patient Demographics of Neuropathology and Stereology Subjects [2, 3, 41]. (DOC $41 \mathrm{~kb})$

Additional file 2: Table S6. Antibodies, suppliers, and usage. (DOC 47 kb) Additional file 3: Table S2. Case Details For Microarray, q-PCR and Biochemistry Series [2, 3, 41]. (DOC $41 \mathrm{~kb}$ )

Additional file 4: Table S5. Taqman q-RT-PCR Assay Details used in determination of mRNA relative levels in primary visual cortex. Assay ID, specific assay identifier; Gene Name, mRNA target of assay. (DOC $41 \mathrm{~kb}$ )

Additional file 5: Table S3. Analysis of pathology related genes in the primary visual cortex in Dementia with Lewy Bodies and Alzheimer's disease. (DOC $30 \mathrm{~kb}$ )

Additional file 6: Figure S1. Neurodegenerative Disease Pathology in the Occipital Lobe in (A) Control and (B) Alzheimer's disease cases. Representative staining for a-synuclein, $A \beta$ (4G8), and hyperphosphorylated tau (AT8) in primary visual cortex (BA17), secondary visual cortex (BA18), and lateral occipital cortex (BA37) in A) elderly normal control or in B) AD individuals. An absence of a-synuclein pathology was seen in BA17 in either AD or controls cases. Similarly, an absence of AT8 (hyperphosphorylated tau) staining was seen in BA17 in controls, but increasing levels were seen in BA17, BA18 and $\mathrm{BA} 37$ in $\mathrm{AD}$. A 3 (4G8 antibody) pathology was present in all cortical regions examined with high levels seen in BA17 in AD cases and in other cortical regions examined. Photomicrographs were taken at $x 2.5$ magnification (upper rows) or at $\times 40$ magnification (lower rows) with scale bars at $1000 \mu \mathrm{m}$ (upper rows) or $50 \mu \mathrm{m}$ (lower rows). (ZIP $1315 \mathrm{~kb}$ )

Additional file 7: Table S7. Functional Systems altered in Primary Visual Cortex in Dementia with Lewy Bodies (DOC 42 kb)

Additional file 8: Table S4. GAD65/67 Mean ( \pm SD) Cell Counts of GABAergic Neurones in the Primary (BA17) and Secondary (BA18) Visual cortex in Dementia with Lewy Bodies and Alzheimer's disease. (DOC $30 \mathrm{~kb}$ )

\section{Competing interests}

The authors declare no perceived conflict of interest. Drs Morris, Khundakar, Hanson, Taylor and Profs Attems and Thomas are in receipt of funding from the Alzheimer's Society and from the National Institutes of Health Research. Dr Morris, Ms Lett, and Profs Attems and Thomas receive grant funding from the Medical Research Council. Prof McKeith has received honoraria from GE 
Healthcare and Roivant as a speaker and is President of the Lewy Body Society. Dr Taylor has acted as a consultant for Lundbeck and received speaker fees from Flynn Pharmaceuticals and GE Healthcare and serves on the Scientific Advisory Committee for the Lewy Body Society. Dr Brownstein has been funded by the NIH and the Children's Tumor Foundation. He has received compensation as VP for Drug Development of Azevan Pharmaceuticals and owns stock in the company, and is a founder and part owner of Pisces Therapeutics and Alluvium Biosciences. He also serves on the Scientific Advisory Boards (SABs) of N-Gene, Intrinsic LifeSciences, and Plasmonics and owns shares of these companies. He chairs the SAB of the Dysautonomia Foundation and is a member of the Board of Directors of the Restless Legs Syndrome Foundation. Prof O'Brien serves on the Scientific Advisory Committee for the Lewy Body Society and has acted as a consultant or received grant income from GE Healthcare, Lilly and TauRx. Prof Turnbull and Dr Lax receive funding from the Wellcome Trust. Mr Erskine is funded by the Yvonne Mairy Bequest, Miss Karyka acknowledges support of the European Union through the Leonardo Da Vinci Scholarship programme.

\section{Authors' contributions}

Dr AAK undertook the stereological analysis of the primary visual cortex and the differential neurone counts of interneurone subtypes. Dr PSH analysed the neuropeptide markers using ELISA, undertook sample preparation and western blotting along with $\mathrm{Mr}$ DE, and with Dr NZL prepared RNA samples and undertook the GPCR. Dr ME along with Dr CMM, Dr CCX and Dr MJB developed the methods for RNA isolation and microarray analysis from post mortem brain. Mr JR, Miss EK, Miss ET and Mrs PS undertook sample preparation and western blotting, Dr SJC provided bioinformatics analysis of the microarray data. Mr AG and Mrs LR provided histopathological analysis of the tissue sections for pathology and pathological diagnosis was provided by Prof JA. Prof PGB, Prof UPM, Ms DJL, Prof DMT, Prof JTO', Dr J-PT, Prof AJT, and Prof IGM provided clinical characterisation of the patient and control cohorts. All the authors provided editorial input to the manuscript. All authors read and approved the final manuscript

\section{Acknowledgements}

This work was supported with funds from the Alzheimer's Society, and from the European Union as part of the FP6 Programme DiMI-Diagnostic Molecular Imaging. Further support was received from the Newcastle University Centre for Brain Ageing and Vitality. The Centre receives grant support from the Biotechnology and Biological Sciences Research Council (BBSRC), the Engineering and Physical Sciences Research Council (EPSRC), the Economic and Social Research Council (ESRC) and the Medical Research Council (MRC), as part of the cross-council Lifelong Health and Wellbeing Initiative (G0700718), the Wellcome Trust Centre for Mitochondrial Research (906919) and the UK's National Institute for Health Research (NIHR) Biomedical Research Centre for Ageing and Age-related disease award to the Newcastle-upon-Tyne Hospitals NHS Foundation Trust. CMM is supported by the UK Department of Health, Alzheimer's Society and UK MRC. AAK is supported by the Alzheimer's Society. EK gratefully acknowledges receipt of a Leonardo Da Vinci Scholarship from the European Union. DE is supported by a bursary from the Yvonne Mairy Bequest. Tissue made available for this study was provided by the Newcastle Brain Tissue Resource, which is supported by the UK MRC, the Alzheimer's Society and Alzheimer's Research Trust through the Brains for Dementia Research Initiative, and an NIHR Biomedical Research Centre Grant in Ageing and Health and NIHR Biomedical Research Unit in Lewy body Dementia. The research was funded by the National Institute for Health Research and the views expressed are those of the authors and not necessarily those of the NHS, the NIHR, or the Department of Health.

\section{Author details}

${ }^{1}$ Edwardson Building, Institute of Neuroscience, Newcastle University, Campus for Ageing and Vitality, Westgate Road, Newcastle upon Tyne NE4 5PL, UK. ${ }^{2}$ Medical Toxicology Centre, Newcastle University, Wolfson Building, Claremont Place, Newcastle NE2 4AA, UK. ${ }^{3}$ Wellcome Trust Centre for Mitochondrial Research, Institute of Neuroscience, Newcastle University, The Medical School, Framlington Place, Newcastle upon Tyne NE2 4HH, UK. ${ }^{4}$ Bioinformatics Support Unit, Newcastle University, Leech Building, Framlington Place, Newcastle upon Tyne NE2 4HH, UK. ${ }^{5}$ University Hospital of Old Age Psychiatry, University Bern, CH 3010 Bern, Switzerland. ${ }^{6}$ Department of Neurology and Clinical Neurophysiology, Academic Hospital
Bogenhausen, Technical University of Munich, Munich, Germany. ${ }^{7}$ Laboratory of Genetics at the National Institute of Mental Health/National Human Genome Research Institute, National Institutes of Health, Bethesda, Maryland MD20892, USA. ${ }^{8}$ Biomedical Research Building, Institute of Neuroscience, Newcastle University, Newcastle University, Westgate Road, Newcastle upon Tyne NE4 5PL, UK. ${ }^{9}$ Department of Psychiatry, University of Cambridge School of Clinical Medicine, Box 189 Level E4 Cambridge Biomedical Campus, Cambridge CB2 OSP, UK.

\section{Received: 10 June 2016 Accepted: 10 June 2016}

Published online: 30 June 2016

\section{References}

1. McKeith IG. Clinical Lewy body syndromes. Ann N Y Acad Sci. 2000;920:1-8.

2. McKeith IG. Consensus guidelines for the clinical and pathologic diagnosis of dementia with Lewy bodies (DLB): report of the Consortium on DLB International Workshop. J Alzheimers Dis. 2006;9(3 Suppl):417-23.

3. McKeith IG, Dickson DW, Lowe J, Emre M, O'Brien JT, Feldman H, et al, Diagnosis and management of dementia with Lewy bodies: third report of the DLB Consortium. Neurology. 2005;65(12):1863-72.

4. Mosimann UP, Rowan EN, Partington CE, Collerton D, Littlewood E, O'Brien JT, et al. Characteristics of visual hallucinations in Parkinson disease dementia and dementia with lewy bodies. Am J Geriatric Psychiatry. 2006; 14(2):153-60.

5. Ffytche DH, Howard RJ. The perceptual consequences of visual loss: 'positive' pathologies of vision. Brain. 1999;122(Pt 7):1247-60.

6. Santhouse AM, Howard RJ. ffytche DH. Visual hallucinatory syndromes and the anatomy of the visual brain. Brain. 2000;123(Pt 10):2055-64.

7. Carter R, Ffytche DH. On visual hallucinations and cortical networks: a transdiagnostic review. J Neurol. 2015;262:1780-90.

8. Archibald NK, Clarke MP, Mosimann UP, Burn DJ. Visual symptoms in Parkinson's disease and Parkinson's disease dementia. Mov Disord. 2011; 26(13):2387-95.

9. Gallagher DA, Parkkinen L, O'Sullivan SS, Spratt A, Shah A, Davey CC, et al. Testing an aetiological model of visual hallucinations in Parkinson's disease. Brain. 134(Pt 11):3299-309

10. Colloby SJ, Fenwick JD, Williams ED, Paling SM, Lobotesis K, Ballard C, et al. A comparison of (99 m)Tc-HMPAO SPET changes in dementia with Lewy bodies and Alzheimer's disease using statistical parametric mapping Eur J Nucl Med Mol Imaging. 2002;29(5):615-22.

11. Lobotesis K, Fenwick JD, Phipps A, Ryman A, Swann A, Ballard C, et al Occipital hypoperfusion on SPECT in dementia with Lewy bodies but not AD. Neurology. 2001;56(5):643-9.

12. Imamura $T$, Ishii $K$, Hirono $N$, Hashimoto M, Tanimukai S, Kazuai H, et al. Visual hallucinations and regional cerebral metabolism in dementia with Lewy bodies (DLB). Neuroreport. 1999;10(9):1903-7.

13. Mosimann UP, Mather G, Wesnes KA, O'Brien JT, Burn DJ, McKeith IG. Visual perception in Parkinson disease dementia and dementia with Lewy bodies. Neurology. 2004;63(11):2091-6.

14. Beyer MK, Larsen JP, Aarsland D. Gray matter atrophy in Parkinson disease with dementia and dementia with Lewy bodies. Neurology. 2007;69(8): 747-54.

15. Burton EJ, McKeith IG, Burn DJ, Williams ED, O'Brien JT. Cerebral atrophy in Parkinson's disease with and without dementia: a comparison with Alzheimer's disease, dementia with Lewy bodies and controls. Brain. 2004; 127(Pt 4):791-800.

16. Delli Pizzi S, Maruotti V, Taylor JP, Franciotti R, Caulo M, Tartaro A, et al. Relevance of subcortical visual pathways disruption to visual symptoms in dementia with Lewy bodies. Cortex. 2014;59:12-21.

17. Watson R, Blamire AM, O'Brien JT. Magnetic resonance imaging in lewy body dementias. Dement Geriatr Cogn Disord. 2009;28(6):493-506.

18. Pereira JB, Junque C, Marti MJ, Ramirez-Ruiz B, Bargallo N, Tolosa E. Neuroanatomical substrate of visuospatial and visuoperceptual impairment in Parkinson's disease. Mov Disord. 2009;24(8):1193-9.

19. Delli Pizzi S, Franciotti $R$, Tartaro A, Caulo M, Thomas A, Onofrj M, et al. Structural alteration of the dorsal visual network in DLB patients with visual hallucinations: a cortical thickness MRI study. PLoS One. 2014;9(1):e86624.

20. Higuchi M, Tashiro M, Arai H, Okamura N, Hara S, Higuchi S, et al. Glucose hypometabolism and neuropathological correlates in brains of dementia with Lewy bodies. Exp Neurol. 2000;162(2):247-56. 
21. Yamamoto R, Iseki E, Murayama N, Minegishi M, Marui W, Togo T, et al. Investigation of Lewy pathology in the visual pathway of brains of dementia with Lewy bodies. J Neurol Sci. 2006;246(1-2):95-101.

22. Yamamoto R, Iseki E, Marui W, Togo T, Katsuse O, Kato M, et al. Nonuniformity in the regional pattern of Lewy pathology in brains of dementia with Lewy bodies. Neuropathology. 2005;25(3):188-94.

23. Armstrong RA. Parkinson's disease and the eye. Ophthalmic Physiol Opt. 1997;17(Suppl 2):S9-16.

24. Collerton D, Perry E, McKeith I. Why people see things that are not there: a novel Perception and Attention Deficit model for recurrent complex visual hallucinations. Behav Brain Sci. 2005;28(6):737-57.

25. Betts $L R$, Taylor $C P$, Sekuler $A B$, Bennett PJ. Aging reduces center-surround antagonism in visual motion processing. Neuron. 2005;45(3):361-6.

26. Bennett PJ, Sekuler $R$, Sekuler $A B$. The effects of aging on motion detection and direction identification. Vision Res. 2007:47(6):799-809.

27. Roudaia E, Bennett PJ, Sekuler AB, Pilz KS. Spatiotemporal properties of apparent motion perception and aging. J Vis. 2010;10(14):5.

28. Klein $\mathrm{R}$, Klein BE, Lee KE. Changes in visual acuity in a population. The Beaver Dam Eye Study. Ophthalmology. 1996;103(8):1169-78.

29. Sekuler $A B$, Bennett PJ, Mamelak M. Effects of aging on the useful field of view. Exp Aging Res. 2000;26(2):103-20.

30. Archibald NK, Clarke MP, Mosimann UP, Burn DJ. Retinal thickness in Parkinson's disease. Parkinsonism Relat Disord. 2011;17(6):431-6.

31. Kravitz DJ, Saleem KS, Baker Cl, Ungerleider LG, Mishkin M. The ventral visual pathway: an expanded neural framework for the processing of object quality. Trends Cogn Sci. 2012;17(1):26-49.

32. Mishkin $M$, Ungerleider LG. Contribution of striate inputs to the visuospatial functions of parieto-preoccipital cortex in monkeys. Behav Brain Res. 1982; 6(1):57-77.

33. Harding AJ, Broe GA, Halliday GM. Visual hallucinations in Lewy body disease relate to Lewy bodies in the temporal lobe. Brain. 2002;125(Pt 2):391-403.

34. Harding AJ, Stimson E, Henderson JM, Halliday GM. Clinical correlates of selective pathology in the amygdala of patients with Parkinson's disease. Brain. 2002:125(Pt 11):2431-45.

35. Ferman TJ, Arvanitakis Z, Fujishiro H, Duara R, Parfitt F, Purdy M, Waters C, Barker W, Graff-Radford NR, Dickson DW. Pathology and temporal onset of visual hallucinations, misperceptions and family misidentification distinguishes dementia with Lewy bodies from Alzheimer's disease. Parkinsonism Relat Disord. 2013;19(2):227-31.

36. Maurage CA, Ruchoux MM, de Vos R, Surguchov A, Destee A. Retinal involvement in dementia with Lewy bodies: a clue to hallucinations? Ann Neurol. 2003;54(4):542-7.

37. O'Brien JT, Colloby SJ, Pakrasi S, Perry EK, Pimlott SL, Wyper DJ, et al. Nicotinic alpha4beta2 receptor binding in dementia with Lewy bodies using 123I-5IA-85380 SPECT demonstrates a link between occipital changes and visual hallucinations. Neuroimage. 2008;40(3):1056-63.

38. Ballard C, Piggott M, Johnson M, Cairns N, Perry R, McKeith I, et al. Delusions associated with elevated muscarinic binding in dementia with Lewy bodies. Ann Neurol. 2000:48(6):868-76.

39. Shimizu S, Hanyu H, Kanetaka H, Iwamoto T, Koizumi K, Abe K. Differentiation of dementia with Lewy bodies from Alzheimer's disease using brain SPECT. Dement Geriatr Cogn Disord. 2005;20(1):25-30.

40. McKhann G, Drachman D, Folstein M, Katzman R, Price D, Stadlan EM. Clinical diagnosis of Alzheimer's disease: report of the NINCDS-ADRDA Work Group under the auspices of Department of Health and Human Services Task Force on Alzheimer's Disease. Neurology. 1984;34(7):939-44.

41. Braak H, Braak E. Staging of Alzheimer's disease-related neurofibrillary changes. Neurobiol Aging. 1995;16(3):271-8. discussion 8-84.

42. Braak H, Del Tredici K, Rub U, de Vos RA, Jansen Steur EN, Braak E. Staging of brain pathology related to sporadic Parkinson's disease. Neurobiol Aging. 2003;24(2):197-211.

43. Thal DR, Rub U, Orantes M, Braak H. Phases of A beta-deposition in the human brain and its relevance for the development of AD. Neurology. 2002; 58(12):1791-800

44. McKhann GM, Knopman DS, Chertkow H, Hyman BT, Jack Jr CR, Kawas CH, et al. The diagnosis of dementia due to Alzheimer's disease: recommendations from the National Institute on Aging-Alzheimer's Association workgroups on diagnostic guidelines for Alzheimer's disease. Alzheimers Dement. 2011;7(3):263-9.

45. Mandler M, Walker L, Santic R, Hanson P, Upadhaya AR, Colloby SJ, et al. Pyroglutamylated amyloid-beta is associated with hyperphosphorylated tau and severity of Alzheimer's disease. Acta Neuropathol. 2014;128(1):67-79.

46. Walker L, McAleese KE, Thomas AJ, Johnson M, Martin-Ruiz C, Parker C, et al. Neuropathologically mixed Alzheimer's and Lewy body disease: burden of pathological protein aggregates differs between clinical phenotypes. Acta Neuropathol. 2015;129(5):729-48.

47. Gundersen HJ, Bendtsen TF, Korbo L, Marcussen N, Moller A, Nielsen K, et al. Some new, simple and efficient stereological methods and their use in pathological research and diagnosis. APMIS. 1988;96(5):379-94.

48. Tandrup T, Gundersen HJ, Jensen EB. The optical rotator. J Microsc. 1997; 186(Pt 2):108-20.

49. Khundakar AA, Morris CM, Oakley AE, Thomas AJ. Cellular pathology within the anterior cingulate cortex of patients with late-life depression: a morphometric study. Psychiatry Res. 2011;194(2):184-9.

50. Khundakar AA, Thomas AJ. Morphometric changes in early- and late-life major depressive disorder: evidence from postmortem studies. International Psychogeriatrics/IPA. 2009;21(5):844-54

51. Gundersen HJ, Jensen EB. The efficiency of systematic sampling in stereology and its prediction. J Microsc. 1987;147(Pt 3):229-63.

52. Lin SM, Du P, Huber W, Kibbe WA. Model-based variance-stabilizing transformation for Illumina microarray data. Nucleic Acids Res. 2008;36(2):e11.

53. Du P, Kibbe WA, Lin SM. lumi: a pipeline for processing Illumina microarray. Bioinformatics. 2008:24(13):1547-8.

54. Ritchie ME, Phipson B, Wu D, Hu Y, Law CW, Shi W, et al. limma powers differential expression analyses for RNA-sequencing and microarray studies. Nucleic Acids Res. 2015;43(7):e47.

55. Benjamini Y, Hochberg Y. Controlling the False Discovery Rate - a Practical and Powerful Approach to Multiple Testing. J Roy Stat Soc B Met. 1995;57(1):289-300.

56. Falcon S, Gentleman R. Using GOstats to test gene lists for GO term association. Bioinformatics. 2007;23(2):257-8.

57. Livak KJ, Schmittgen TD. Analysis of relative gene expression data using real-time quantitative PCR and the 2(-Delta Delta C(T)) Method. Methods. 2001;25(4):402-8.

58. Kingsbury AE, Bandopadhyay R, Silveira-Moriyama L, Ayling H, Kallis C, Sterlacci W, et al. Brain stem pathology in Parkinson's disease: an evaluation of the Braak staging model. Mov Disord. 2010;25(15):2508-15.

59. Taylor JP, Firbank M, O'Brien JT. Visual cortical excitability in dementia with Lewy bodies. Br J Psychiatry. 2015;208:497-8.

60. Kneussel M, Haverkamp S, Fuhrmann JC, Wang H, Wassle H, Olsen RW, et al. The gamma-aminobutyric acid type A receptor (GABAAR)-associated protein GABARAP interacts with gephyrin but is not involved in receptor anchoring at the synapse. Proc Natl Acad Sci U S A. 2000;97(15):8594-9.

61. Fritschy JM, Panzanelli P, Tyagarajan SK. Molecular and functional heterogeneity of GABAergic synapses. Cell Mol Life Sci. 2012;69(15):2485-99.

62. Toledo JB, Gopal P, Raible K, Irwin DJ, Brettschneider J, Sedor S, et al. Pathological alpha-synuclein distribution in subjects with coincident Alzheimer's and Lewy body pathology. Acta Neuropathol. 2016;131(3):393-409.

63. Taylor JP, Firbank MJ, He J, Barnett N, Pearce S, Livingstone A, et al. Visual cortex in dementia with Lewy bodies: magnetic resonance imaging study. Br J Psychiatry. 2012;200(6):491-8.

64. Watson R, Colloby SJ, Blamire AM, O'Brien JT. Assessment of regional gray matter loss in dementia with Lewy bodies: a surface-based MRI analysis. Am J Geriatr Psychiatry. 2014;23(1):38-46.

65. Nobili F, Arnaldi D, Campus C, Ferrara M, De Carli F, Brugnolo A, et al. Brain perfusion correlates of cognitive and nigrostriatal functions in de novo Parkinson's disease. Eur J Nucl Med Mol Imaging. 2011;38(12):2209-18.

66. Melzer TR, Watts R, MacAskill MR, Pearson JF, Rueger S, Pitcher TL, et al. Arterial spin labelling reveals an abnormal cerebral perfusion pattern in Parkinson's disease. Brain. 2011;134(Pt 3):845-55.

67. Matsui H, Nishinaka K, Oda M, Hara N, Komatsu K, Kubori T, et al. Hypoperfusion of the visual pathway in parkinsonian patients with visual hallucinations. Mov Disord. 2006:21(12):2140-4.

68. Tropea D, Kreiman G, Lyckman A, Mukherjee S, Yu H, Horng S, et al. Gene expression changes and molecular pathways mediating activity-dependent plasticity in visual cortex. Nat Neurosci. 2006;9(5):660-8.

69. Leventhal AG, Hirsch HV. Effects of visual deprivation upon the morphology of retinal ganglion cells projecting to the dorsal lateral geniculate nucleus of the cat. J Neurosci. 1983;3(2):332-44.

70. Tropea D, Majewska AK, Garcia R, Sur M. Structural dynamics of synapses in vivo correlate with functional changes during experience-dependent plasticity in visual cortex. J Neurosci. 2010;30(33):11086-95. 
71. Chen JL, Lin WC, Cha JW, So PT, Kubota Y, Nedivi E. Structural basis for the role of inhibition in facilitating adult brain plasticity. Nat Neurosci. 2011; 14(5):587-94.

72. Keck T, Scheuss V, Jacobsen RI, Wierenga CJ, Eysel UT, Bonhoeffer T, et al. Loss of sensory input causes rapid structural changes of inhibitory neurons in adult mouse visual cortex. Neuron. 2011;71(5):869-82.

73. Lunghi C, Emir UE, Morrone MC, Bridge H. Short-Term Monocular Deprivation Alters GABA in the Adult Human Visual Cortex. Current Biology. 2015;25:1496-501.

74. Webster MJ, Ungerleider LG, Bachevalier J. Development and plasticity of the neural circuitry underlying visual recognition memory. Can J Physiol Pharmacol. 1995;73(9):1364-71.

75. Webster MJ, Bachevalier J, Ungerleider LG. Transient subcortical connections of inferior temporal areas TE and TEO in infant macaque monkeys. J Comp Neurol. 1995:352(2):213-26.

76. Webster MJ, Bachevalier J, Ungerleider LG. Subcortical connections of inferior temporal areas TE and TEO in macaque monkeys. J Comp Neurol. 1993;335(1):73-91.

77. Webster MJ, Bachevalier J, Ungerleider LG. Connections of inferior temporal areas TEO and TE with parietal and frontal cortex in macaque monkeys. Cereb Cortex. 1994:4(5):470-83.

78. Wood JS, Firbank MJ, Mosimann UP, Watson R, Barber R, Blamire AM, O'Brien JT. Testing visual perception in dementia with Lewy bodies and Alzheimer disease. Am J Geriatr Psychiatry. 2013;21(6):501-8.

79. Cancedda L, Putignano E, Sale A, Viegi A, Berardi N, Maffei L. Acceleration of visual system development by environmental enrichment. J Neurosci. 2004; 24(20):4840-8.

80. Castren E, Zafra F, Thoenen H, Lindholm D. Light regulates expression of brain-derived neurotrophic factor mRNA in rat visual cortex. Proc Natl Acad Sci U S A. 1992:89(20):9444-8.

81. Abidin I, Kohler T, Weiler E, Zoidl G, Eysel UT, Lessmann V, et al. Reduced presynaptic efficiency of excitatory synaptic transmission impairs LTP in the visual cortex of BDNF-heterozygous mice. Eur J Neurosci. 2006;24(12):3519-31.

82. Webster MJ, Ungerleider LG, Bachevalier J. Lesions of inferior temporal area TE in infant monkeys alter cortico-amygdalar projections. Neuroreport. 1991; 2(12):769-72.

83. Moreno-Ramos T, Benito-Leon J, Villarejo A, Bermejo-Pareja F. Retinal nerve fiber layer thinning in dementia associated with Parkinson's disease, dementia with Lewy bodies, and Alzheimer's disease. J Alzheimers Dis. 2013;34(3):659-64.

84. Erskine D, Taylor JP, Firbank MJ, Patterson L, Onofrj M, O'Brien JT, et al. Changes to the lateral geniculate nucleus in Alzheimer's disease but not dementia with Lewy bodies. Neuropathol Appl Neurobiol. 2015;42:366-76.

85. Onofrj M, Taylor JP, Monaco D, Franciotti R, Anzellotti F, Bonanni L, et al. Visual hallucinations in PD and Lewy body dementias: old and new hypotheses. Behav Neurol. 2013;27(4):479-93.

86. Mori T, Ikeda M, Fukuhara R, Nestor PJ, Tanabe $H$. Correlation of visual hallucinations with occipital rCBF changes by donepezil in DLB. Neurology. 2006:66(6):935-7.

87. Kantarci K, Lowe VJ, Boeve BF, Weigand SD, Senjem ML, Przybelski SA, et al. Multimodality imaging characteristics of dementia with Lewy bodies. Neurobiol Aging. 2012;33(9):2091-105.

88. Mukaetova-Ladinska EB, Andras A, Milne J, Abdel-All Z, Borr I, Jaros E, et al. Synaptic proteins and choline acetyltransferase loss in visual cortex in dementia with Lewy bodies. J Neuropathol Exp Neurol. 2013;72(1):53-60.

89. Bayes A, Collins MO, Galtrey CM, Simonnet C, Roy M, Croning MD, et al. Human post-mortem synapse proteome integrity screening for proteomic studies of postsynaptic complexes. Mol Brain. 2014;7:88.

90. Bronk P, Deak F, Wilson MC, Liu X, Sudhof TC, Kavalali ET. Differential effects of SNAP-25 deletion on Ca2+-dependent and $\mathrm{Ca} 2+$-independent neurotransmission. J Neurophysiol. 2007;98(2):794-806.

91. Samuel W, Alford M, Hofstetter CR, Hansen L. Dementia with Lewy bodies versus pure Alzheimer disease: differences in cognition, neuropathology, cholinergic dysfunction, and synapse density. J Neuropathol Exp Neurol. 1997;56(5):499-508.

92. Webster MJ, Ungerleider LG, Bachevalier J. Connections of inferior temporal areas TE and TEO with medial temporal-lobe structures in infant and adult monkeys. J Neurosci. 1991:11(4):1095-116.

93. Hunt CA, Schenker $\amalg$, Kennedy MB. PSD-95 is associated with the postsynaptic density and not with the presynaptic membrane at forebrain synapses. J Neurosci. 1996;16(4):1380-8.
94. Lewis DA, Campbell MJ, Terry RD, Morrison JH. Laminar and regional distributions of neurofibrillary tangles and neuritic plaques in Alzheimer's disease: a quantitative study of visual and auditory cortices. J Neurosci. 1987:7(6):1799-808.

95. Meppelink AM, de Jong BM, Renken $\mathrm{R}$, Leenders $\mathrm{KL}$, Cornelissen FW, van Laar T. Impaired visual processing preceding image recognition in Parkinson's disease patients with visual hallucinations. Brain. 2009;132(Pt 11): 2980-93.

96. Taylor JP, Firbank M, Barnett N, Pearce S, Livingstone A, Mosimann U, et al. Visual hallucinations in dementia with Lewy bodies: transcranial magnetic stimulation study. Br J Psychiatry. 2011:199(6):492-500.

97. Volman V, Behrens MM, Sejnowski TJ. Downregulation of parvalbumin at cortical GABA synapses reduces network gamma oscillatory activity. J Neurosci. 2011;31(49):18137-48.

98. Atallah BV, Bruns W, Carandini M, Scanziani M. Parvalbumin-expressing interneurons linearly transform cortical responses to visual stimuli. Neuron. 2012;73(1):159-70.

99. Ibarretxe-Bilbao N, Ramirez-Ruiz B, Junque C, Marti MJ, Valldeoriola F, Bargallo N, et al. Differential progression of brain atrophy in Parkinson's disease with and without visual hallucinations. J Neurol Neurosurg Psychiatry. 2010;81(6):650-7.

100. Kantarci K, Avula R, Senjem ML, Samikoglu AR, Zhang B, Weigand SD, et al. Dementia with Lewy bodies and Alzheimer disease: neurodegenerative patterns characterized by DTI. Neurology. 2010;74(22):1814-21.

101. Jefferis JM, Clarke MP, Taylor JP. Effect of cataract surgery on cognition, mood, and visual hallucinations in older adults. J Cataract Refract Surg. 2015:41(6):1241-7.

102. Mosimann UP, Collerton D, Dudley R, Meyer TD, Graham G, Dean JL, et al. A semi-structured interview to assess visual hallucinations in older people. Int J Geriatr Psychiatry. 2008;23(7):712-8

\section{Submit your next manuscript to BioMed Central and we will help you at every step:}

- We accept pre-submission inquiries

- Our selector tool helps you to find the most relevant journal

- We provide round the clock customer support

- Convenient online submission

- Thorough peer review

- Inclusion in PubMed and all major indexing services

- Maximum visibility for your research

Submit your manuscript at www.biomedcentral.com/submit 